\title{
MÁRLIO AGUIAR
}

\section{A IURISDICTIO E O IUS DICERE NO PENSAMENTO JURÍDICO E INSTITUCIONAL ROMANO}

Tese de Doutorado

Orientador: Professor Doutor Hélcio Maciel França Madeira

UNIVERSIDADE DE SÃO PAULO

FACULDADE DE DIREITO

Largo São Francisco

São Paulo, SP 


\section{MÁRLIO AGUIAR}

\section{A IURISDICTIO E O IUS DICERE NO PENSAMENTO JURÍDICO E INSTITUCIONAL ROMANO:}

Tese de Doutorado apresentada à Banca Examinadora do Programa de Pós-Graduação em Direito, da Faculdade de Direito da Universidade de São Paulo, como exigência parcial para a obtenção do título de Doutor em Direito, na área de concentração Direito Civil, sob a orientação do Prof. Doutor Hélcio Maciel França Madeira.

UNIVERSIDADE DE SÃO PAULO

FACULDADE DE DIREITO

Largo São Francisco

São Paulo, SP 
Catalogação da Publicação

Serviço de Biblioteca e Documentação

Faculdade de Direito da Universidade de São Paulo

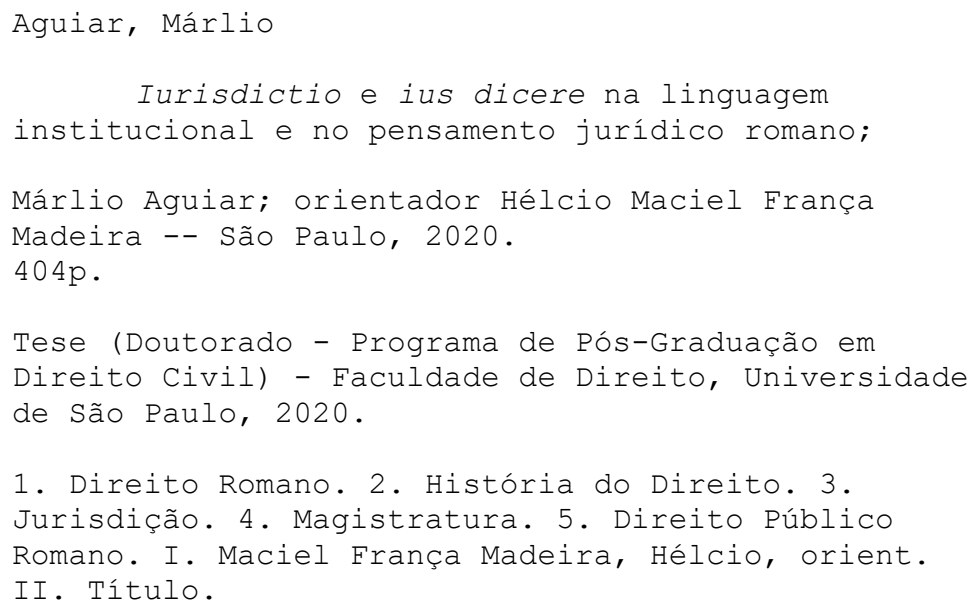




\section{AGRADECIMENTOS}

Não sou nada.

Nunca serei nada. Não posso querer ser nada. À parte isso, tenho em mim todos os sonhos do mundo...

Um ponto numa linha. Essa tese reflete a trajetória que iniciei em meados do ano de 2009 quando ingressei no ambiente acadêmico. E quão longínquo esse ano agora parece!, quando possibilidades e certezas compunham uma dança que não parecia poder ter fim. Apenas conjecturo para onde foram todas aquelas gloriosas convicções a respeito de como eu e o mundo funcionávamos. Como quando riscou no papel aqueles belos versos: $A$ aprendizagem que me deram, Desci pela janela das traseiras da casa, Fui até o campo com grandes propósitos, Mas lá encontrei só ervas e árvores. É diante do fato mais humano comprovado no laboratório do mundo - que ninguém vive sozinho -, eu não poderia deixar de agradecer àqueles que tornaram minha história mais interessante.

Não poderia deixar de começar senão por aqueles que do começo ao fim propiciaram minha educação e minha formação, e que de modo absolutamente irrestrito sempre apoiaram minhas iniciativas do começo ao fim. Aos meus pais, deixo aqui não apenas o meu obrigado - tacanho, insuficiente e tão sincero -, mas minha dívida pelo amor e cuidado que me deram a conhecer.

Agradeço ao meu orientador, Prof. Hélcio Maciel França Madeira, pelo encorajamento e pela generosidade que me trouxeram ao pátio das Arcadas, pelos lembretes constantes, mas sempre gentis, da importância da autonomia intelectual e da seriedade acadêmica, do valor dos antigos livros e de suas entrelinhas.

Sem dúvida não pela última vez, registro minha gratidão para com o Prof. José Isaac Pilati, iuris disceptator, que esteve lá desde o começo, guiando essa imensa aventura nas ruínas textuais da velha Urbe, e por me fornecer exemplum de irrestrita dedicação à Universidade (mais do que nunca ela se faz necessária!) e do entusiasmo sem limites que tantas contribuições rendem à romanística e às letras jurídicas pátrias. 
Amizades e parcerias podem surgir ao acaso na vida acadêmica, mas somente as boas realmente vicejam. Assim, ao Prof. Tiago Losso, há muito um caro amigo, registro meu agradecimento pelos anos de parceria, pelo constante bom humor e pela disposição inesgotável em dar continuidade a nossos projetos comuns em prol de uma história intelectual romana que faça jus ao passado sem perder de vista o presente. Há muito por vir!

Expresso mais uma vez gratidão com todos os professores e pesquisadores que de alguma forma - às vezes, com uma cópia de livro indispensável; por vezes, com um simples bom dia bem-humorado - contribuíram para essa tese. Entre eles, destaco a generosidade do Prof. Kaius Tuori da University of Helsinki, bem como a todos que forneceram sugestões e críticas absolutamente interessantes à época de minha qualificação.

Felizmente o nexum foi há muito abolido, pois minha dívida com vocês, Felipe e Bruno, nunca seria completamente paga nem com uma longeva vida de servidão. Ao longo de uma década (!) de trajetória acadêmica sempre encontrei em sua companhia o antídoto para a solidão humana, a resistência ao isolamento intelectual que se avizinha em nossas rotinas. Em nossa comunhão de perguntas (e não de respostas, o que costuma ser o caminho mais fácil na academia) encontro o ponto mais interessante da minha trajetória acadêmica. Das vitórias e comemorações aos repetidos dessabores desses dois últimos anni horribiles recebi de ambos a prova de que a amicitia é uma das poucas barreiras entre o homem e o abismo, uma das raras conexões entre o devir e um sentido. Muito longe de ser um Cícero, pude experimentar, como este, o alívio das correspondências fieis com um Ático e um Quinto. Obrigado, meus caros, por tudo.

Minha estadia paulistana é indissociável da gloriosa República 193 dividida com o Walter. Pela resiliência diante de minhas excentricidades, pela disposição em ouvir meus rabugentos desabafos das quintas-feiras, pelo companheirismo das aulas de alemão (Ich möchte ein Kaffe, bitte...) e por todas as seríssimas discussões a respeito dos Cavaleiros do Zodíaco, só me resta agradecer por ter participado de minha experiência de vida em São Paulo.

A melhor maneira que aprendi para identificar os verdadeiros amigos: a presença mesmo na ausência. Quando eu precisei, nunca estive realmente sozinho. Verdade seja dita, sei que é nada menos do que uma grande fortuna e o maior patrimônio humano que consegui 
adquirir nesses anos foram vocês: Ferreira, Perez, Davi, Freitas, Plínio, Silveira, Bena, Moser, Thiago, Diego, Carol, Sara, Arielle, Maurício e Cássio. Obrigado, pessoal, hoje e sempre.

Quando achamos que sabemos para onde nossa vida se encaminha, ela nos mostra quem é que manda. Algumas vezes a surpresa é das boas. Poderia saber naquele setembro de 2018 quão afortunado eu seria com meu primeiro ambiente de trabalho? Certamente não. Ao doutor Elleston Lissandro Canali, manifesto minha gratidão pelo apoio concedido às minhas atividades acadêmicas, manifestadas desde antes da posse, tornando possível a minha rotina entre os corredores do fórum e as páginas da tese. Aos colegas que preenchem desde então meu dia-a-dia com risadas, companheirismo e café - Bernardo, João, Arthur, Samira e John - meu mais sincero obrigado. Quanto a você, Ana Karina, faltam-me palavras que expressem o que seu apoio e carinho significaram para mim desde então. Eu colocaria todos vocês no meu altar dos deuses manes com muito orgulho.

E por falar em surpresas inusitadas...

Você foi a maior (por mais que seja pequena!), a mais inesperada e a mais bela de todas elas, Camilla. Suum quoique amorem, mihi meum. 
nec per se quemquam tempus sentire fatendumst semotum ab rerum motu placidaque quiete

flectere si nequeo superos, Acheronta movebo.

etiam si mille hoc dixissent. 


\section{RESUMO}

Esta tese tem o objetivo de compreender a formação e o uso das expressões "ius dicere" e "iurisdictio" na história do pensamento jurídico entre a República e o Principado. Para tanto, parte-se do pressuposto de que essas palavras podem ser tomadas como conceitos históricos básicos (Geschichtliche Grundbegriff), isto é, de que são complexos semânticos mobilizados tanto para explicar a realidade social, jurídica e institucional através da linguagem da iurisprudentia, mas que também funcionam como conceitos de cunho normativo, cunhados para ordenar e intervir nas práticas jurídicas. Ciente, no entanto, das descontinuidades temporais e conceituais entre a iurisdictio romana e a jurisdição moderna, opta-se por começar a história dessas expressões pelo caminho reverso. Na primeira parte do trabalho analisam-se os dois períodos subsequentes na história do pensamento jurídico europeu que (re)interpretaram a iurisdictio romana em seus próprios termos e de acordo com seu tempo. No primeiro capítulo, dedicamos atenção ao baixo medievo do ius commune, especificamente ao tratamento dos conceitos de iurisdictio e imperium na produção das escolas dos glosadores e comentadores. No segundo capítulo, passando aos primórdios do pensamento jurídico moderno, rumamos para os integrantes do humanismo jurídico francês do século XVI, analisando as críticas que fazem às soluções dos juristas medievais e à intrincada tarefa de readequar aqueles conceitos para a nova realidade social e jurídica que emergia: o paradigma da soberania e do Estado modernos. A segunda parte do trabalho se dedica a esses conceitos na história de Roma. O terceiro capítulo trata da iurisdictio romana do ponto de vista de sua história institucional, passando em revista as magistraturas e funções ligadas ao poder de aplicar o direito (em sentido amplo) desde os tempos monárquicos até o fim do Principado. No quartoo capítulo, por fim, à luz dessa realidade fática desse poder, a tese investiga através da análise de fontes oriundas da linguagem institucional e da literatura jurídica o modo como os romanos desses períodos conceberam, delinearam e fizeram uso dos conceitos de ius dicere e iurisdictio. Conclui-se através dessas fontes que os usos linguísticos dessas expressões foram diversos ao longo do período. No período tardorrepublicano a expressão "ius dicere" estava ligada primordialmente a um conjunto amplo de poderes na linguagem institucional e legislativa, não completamente definidos e ligados diretamente à autonomia juridicente dos magistrados. No período do Principado iurisdictio passa a ser um conceito utilizado para expressar as delimitações dos poderes dos governadores, praefecti e magistrados, tanto no sentido de limites espaciais ou de competência material de sua iurisdictio, quanto no sentido de especificar os modos pelos quais a jurisdição poderia ser exercida, assim como os poderes e prerrogativas que estavam ou não implicadas na posse da iurisdictio. Tal mudança semântica se dá de modo definitivo com os juristas pertencentes à corte da dinastia dos Severos, e se materializa especialmente através da criação de um conjunto mais coerentes e exaustivo de normas para a delegação de jurisdição (iurisdictio mandata) nos textos de Papiniano, Paulo e Ulpiano.

Palavras-Chave: Direito Público Romano. História do Direito Romano. Iurisdictio. Ius dicere. Ius reddere. Ius dicentis officium. Imperium. Humanismo jurídico. 


\section{RIASSUNTO}

Questa tesi ha come scopo capire la formazione e l'uso delle espressioni "ius dicere" e "iurisdictio" nella storia del pensiero giuridico tra la Repubblica ed il Principato. Così, si parte dal presupposto che queste parole possano essere considerate come concetti storici basici (Geschichtliche Grundbegriff), cioè, complessi semantici mobilitati tanto per spiegare la realtà sociale, giuridica ed istituzionale attraverso il linguaggio dell'iurisprudentia, ma funzionano anche come concetti di impronta normativa, coniati per ordinare ed intervenire nelle pratiche giuridiche. Consapevole delle discontinuità temporali e concettuali tra l'iurisdictio romana e la giurisdizione moderna, si sceglie per cominciare la storia di queste espressioni attraverso un cammino reverso. Nella prima parte del lavoro si analizzano i due periodi successivi nella storia del pensiero europeo che hanno (re)interpretato l'iurisdictio romana nei suoi propri termini e in accordo con il suo tempo. Nel primo capitolo, dedichiamo l'attenzione verso il basso medioevo ius commune, più in specifico all'elaborazione dei concetti di iurisdictio e imperium nella produzione delle scuole dei Glossatori e Commentatori. Nel secondo capitolo, passando per i primordi del pensiero giuridico e moderno, ci dirigiamo verso gli integranti dell'umanesimo giuridico francese del XVI secolo, analizzando le critiche che essi fanno alle soluzioni dei giuristi medioevali e della cospicua impresa di adeguare quelli concetti per la nuova realtà giuridica che emergeva: il paradigma della sovranità e degli Stati moderni. La seconda parte del lavoro si dedica a questi concetti nella storia di Roma. Il terzo capitolo tratta dell'iurisdictio romana dal punto di vista della sua storia istituzionale, perquisendo le magistrature e funzioni collegate al potere di applicare il diritto (in senso ampio) dai tempi monarchici alla fine del Principato. $\mathrm{Nel}$ quarto capitolo, infine, sotto la luce di questa realtà fattuale di questo potere, la tesi indaga attraverso l'analisi delle fonti originarie nel linguaggio istituzionale e della letteratura giuridica la maniera con la quale i romani di questo periodo hanno concepito, hanno tracciato e hanno utilizzato i concetti di ius dicere e iurisdictio. Si conclude attraverso queste fonti che gli usi linguistici di queste due espressioni sono stati diversi attraverso il periodo. Nell'età tardo-repubblicana l'espressione "ius dicere" era collegata essenzialmente ad un ampio insieme di poteri nel linguaggio istituzionale e legislativo, non completamente definiti e collegati direttamente all'autonomia giurisdicente del magistrato. Nel periodo del Principato, iurisdictio diventa un concetto utilizzato per esprimere le delimitazioni dei poteri dei governatori, praefecti e magistrati, tanto nel senso dei limiti spaziali o di competenza materiale della sua iurisdictio quanto nel senso di specificare i modi per i quali la giurisdizione potrebbe essere esercitata, così come i poteri e prerogative che erano o non coinvolte nel possesso dell'iurisdictio. Tale cambiamento semantico si deve in maniera definita con i giuristi appartenenti alla corte della Dinastia dei Severi e se materializza principalmente attraverso la creazione di un insieme più coerente e esaustivo di norme per la delega di giurisdizione (iurisdictio mandata) nei testi di Papiniano, Paolo e Ulpiano.

Parola-chiavi: Diritto Pubblico Romano. Storia del Diritto Romano. Iurisdictio. Ius dicere. Ius reddere. Ius dicentis officium. Imperium. Umanesimo giuridico. 


\begin{abstract}
This thesis intents to understand the formation and the use of the words "ius dicere" and "iurisdictio" in the history of roman legal thought between the Republic and the High Empire. To achieve this purpose, we have assumed that these words could be understood as basic historical concepts (Geschichtliche Grundbegriff). That means, those expressions are semantic fields used in two ways: to explain the legal and institutional reality (through the language of iurisprudentia); but also, to intervene in the legal practices and order the social reality. Aware of the discontinuities between the Roman "iurisdictio" and modern "jurisdiction" concept, we choose chooses to begin the history of these words by a reverse path. In the first part of the thesis we analyse the two subsequent periods in the European history of the legal thought, because in the both periods the concept of "iurisdictio" was interpreted and re-analysed in different terms and with concerns. In the chapter 1 we concentrate our research in the Latte Middle Ages and its us commune, specifically focusing on the ways how Roman words and institutes like iurisdictio and imperium were understood by the legal Glossators and the Commentators scholars. The chapter 2 is all about the very beginnings of the modern legal thought in the works of the French legal humanists of the $16^{\text {th }}$ century. Once again, we were concerned about how they thought, how they critized the legal opinions of their medieval predecessors and specially how they deal with the very hard task of readjust these concepts again to a new social and legal reality: the modern State and the modern concepts of sovereignty and jurisdiction. Moving into the second part of the thesis we will encounter these same concepts once again, but finally in the Roman legal history. Chapter 3 takes an institutional historical approach to deals with iurisdictio, analysing the Roman magistrates and their capabilities about power and administration of justice, since the regal period of Roman history until the end of the High Empire. In the chapter 4, after considering all that factual reality of power and jurisdictional capabilities presented in chapter 3, we arrive the proper analysis of the historical sources related to institutional thought and legal literature and its uses of the words ius dicere and iurisdictio. From the analysis of the linguistic and semantic uses of those concepts it was concluded a semantic shift. In the Late Republic the ius dicere was primarily used to express a broader sense of powers, not completely delimited, but directly linked with the idea of autonomous jurisdictional practices. After in the High Empire period the iurisdictio becomes something else: a concept used to express or to define the limitations of the jurisdictional and coercive powers of the public authorities such provincial governors, magistrates and praefecti, either in terms of spatial limits or material limits to the iurisdictio's exercise. In this sense the language of the Roman jurists also specified by this time what kind of powers were included or not in the iurisdictio. This semantic change takes a definitive form in the final period of the High Empire, precisely with the Severian jurists of the emperor consilium. We conclude appoint how this conceptual change were compelled by the necessity of a more coherent set of norms concerning about the transfer of jurisdiction (iurisdictio mandata) in the works of Papinian, Paul and Ulpian.
\end{abstract}

Key-words: Public Roman Law. Legal Roman History. Iurisdictio. Ius dicere. Ius reddere. Ius dicentis officium. Imperium. French Legal Humanism. 


\section{SUMÁRIO}

Lista de Figuras

Lista de Abreviaturas

Introdução

PARTE I

Capítulo I. A iurisdictio no pensamento jurídico medieval

Primo limine $\quad 5$

I. A ciência jurídica medieval: a ordem e o direito 8

1.1. Os glosadores $\quad 21$

1.2. Os comentadores ou conciliadores $\quad 26$

II. A ciência jurídica medieval e o fenômeno juridicente 30

2.1. A primeira inovação medieval na matéria: definir a iurisdictio 35

2.2. Iurisdictio quid fit: as definições qualitativas de iurisdictio entre os glosadores $\quad 40$

Capítulo II. A iurisdictio na aurora da Modernidade: do humanismo jurídica à Bodin (séc. XVI)

Primo limine

I. Renascimento, Estado e Modernidade na virada do Quattrocento

II. Derrubando gigantes e conversando com fantasmas: o Humanismo Jurídico do (moderno!) século XVI

III. O imperium contra-ataca: a redefinição humanista de iurisdictio

3.1. Disputatio de iurisdictione: a teoria humanista do poder público 115

IV. Jean Bodin e a iurisdictio: a emergência da teoria da soberania 148

4.1. Bodin e o humanismo jurídico $\quad 150$

4.2. O Methodus $(1566,1672)$ : imperium, iurisdictio e a primeira aparição da soberania através de uma História comparada do Direito

4.3. Da arbor iurisdictionis medieval para a "arbor officiorum" moderna: maiestas, iurisdictio e imperium nos Seis Livros sobre a República (1576-1586)

4.4. Soberania e pensamento jurídico moderno: um fecho

\section{PARTE II}

\section{Capítulo III. O fenômeno juridicente na história jurídica e institucional de Roma 180}

Primo limine

I. O fenômeno juridicente na Roma arcaica (séculos VIII-VI a.C.) 183

1.1. Os reis e o poder juridicente arcaico

1.2. Os primeiros auxiliares juridicentes: os duumviri perduellionis, os quaestores parricidii e o praefectus Urbi

1.3. Em Roma e com os deuses: os colégios sacerdotais e o poder juridicente 196

1.4. Algumas conclusões

II. O poder juridicente ao longo da República (VI-I a.C.)

2.1. O panorama constitucional do período republicano: novas instituições e o poder juridicente

2.1.1. A velha República: da expulsão dos reis (509 a.C.) ao compromisso institucional 204 das leges Liciniae Sextiae (367 a.C.)

2.1.2. A República, das leges Liciniae Sextiae (367 a.C.) à lex Aebutia (c. 100 a.C.) 211

2.1.3. A República tardia: a institucionalização do exercício do poder 224

2.2. Em Roma: o poder juridicente das magistraturas 228

2.2.1. Cônsules, ditadores e tribunos consulares 228

2.2.2. A pretura republicana, o ius dicere e a iurisdictio $\quad 234$

2.2.2.1. A atuação juridicente do pretor urbano $\quad 234$

2.2.2.2. O pretor peregrino e as demais preturas republicanas 244 
$\begin{array}{ll}2.2 .3 .1 \text {. Os edis } & 247\end{array}$

2.2.3.2. Os tribunos da plebe e os udicia populi 249

$\begin{array}{ll}2.2 .3 .3 . \text { Os quaestores aerarii } & 251\end{array}$

2.2.3.4. Tresviri capitales $\quad 252$

2.2.4. Os juízes e os colégios judicantes: iudices, arbitri, decemviri stilitibus iudicandis, centumviri, recuperatores

2.3. Fora de Roma: o ius dicere na Itália e no além-mar

2,3,1, Os praefecti e os magistrados juridicentes nos municipia e coloniae 256

2.3.2. Promagistrados e provinciae na República 264

III. O Principado e a iurisdictio, de Augusto aos Severo 266

3.1. O poder juridicente do princeps e a cognitio extra ordinem 266

3.2. Em Roma: os auxiliares e delegados do princeps $\quad 274$

3.2.1. Velhos magistrados e novos pretores (fideicommissarii, tutelaris, de liberalibus 274 causis)

3.2.2. As prefeituras imperiais $\quad 277$

3.3. Fora de Roma: o ius dicere nos confins do Império 279

3.3.1, A descentralização da cognitio imperial nos munícipios: legati pro praetore, procuratore Caesaris, iuridici e correctores $\quad 279$

3.3.2. Procônsules, praeses provinciales e o praefectus Aegypti 281

$\begin{array}{ll}\text { 3.4. Fecho do capítulo } & 284\end{array}$

Capítulo IV. O conceito de iurisdictio na história do pensamento jurídico romano 286 Primo limine $\quad 286$

I. O conceito de iurisdictio na linguagem institucional da República: poder e autonomia em palavras

1.1. Fontes epigráficas, leges e plebiscita da República $\quad 289$

$\begin{array}{ll}\text { 1.2. Fontes epigráficas (II): as leges flavianas } & 308\end{array}$

$\begin{array}{ll}\text { 1.3. Fontes literárias } & 315\end{array}$

1.3.1. Ius dicere, forum e autoridade: o exercício juridicente autônomo 316

1.3.2. Solum, ius dicere e status jurídico: a iurisdictio como prerrogativa de cidadania 327

II. As palavras e o poder. Os conceitos de ius dicere e iurisdictio na linguagem jurídica no Principado

2.1. A iurisdictio: qual história? Considerações introdutórias às fontes do Digesto

2.2. História e fato: iurisdictio, ius dicere e ius edicendi na literatura jurídica entre Pompônio e Gaio

2.3. A iurisdictio mandata como estatuto geral da iurisdictio? Ius dicere e iurisdictionem mandare na literatura jurídica da era dos Severos

2.4. Em fecho: iurisdictio mandata e imperium

Referências Bibliográficas

$\begin{array}{ll}\text { Fontes primárias consultadas - autores/juristas medievais } & 373\end{array}$

$\begin{array}{ll}\text { Fontes Primárias consultadas - autores/juristas modernos } & 374\end{array}$

$\begin{array}{ll}\text { Bibliografia contemporânea } & 375\end{array}$

$\begin{array}{ll}\text { Índice de Fontes } & 390\end{array}$ 


\section{LISTA DE FIGURAS}

Fig. 1 "Diuisiones, et declarationes iurisdictionum" (= Arbor p. 6 iurisdictionum) in Bartolo da Sasoferrato, in primam [secundam] D. veteris (1590), a fronte rubrica D. 2.

Fig. 2 "Schema potestatis" in Jean Tavard, de iurisdictione et imperio p. 143 (1557), capita XVII. 


\section{LISTA DE ABREVIATURAS}

\section{I) FONTES E COMPILAÇÕES}

C. $=$ Codex Iustinianus

CIL $=$ Corpus inscriptionum latinarum

CILA $=$ Corpus de inscriptiones latinas de Andalicía

Coll. = Collatio legum Mosaicorum et Romanorum

D. $=$ Digesta $=$ Pandectas

FIRA $=$ Fontes iuris romani anteiustiniani

FRS = The Fragments of the Roman Historians

Gai. = Gai institutiones

I. $\quad=$ Institutiones Iustiniani

MHM = Monumenta Germinae Historica

Nov. = Novellae Iustiniani

RIS = Rerum Italicarum Scriptores

RS = Roman Statutes

SAG = Scripta anecdota glossatorum

SAAG = Scripta anecdota antiquorum glossatorum.

TAARHI = Thesaurum Antiquitatum Romanorum et Historiarum Italia

XII Tab. = Lex XII Tabularum

Vat. Frag. = Fragmenta Vaticana 


\section{II) PERIÓDICOS, COLETÂNEAS E COLEÇÕES}

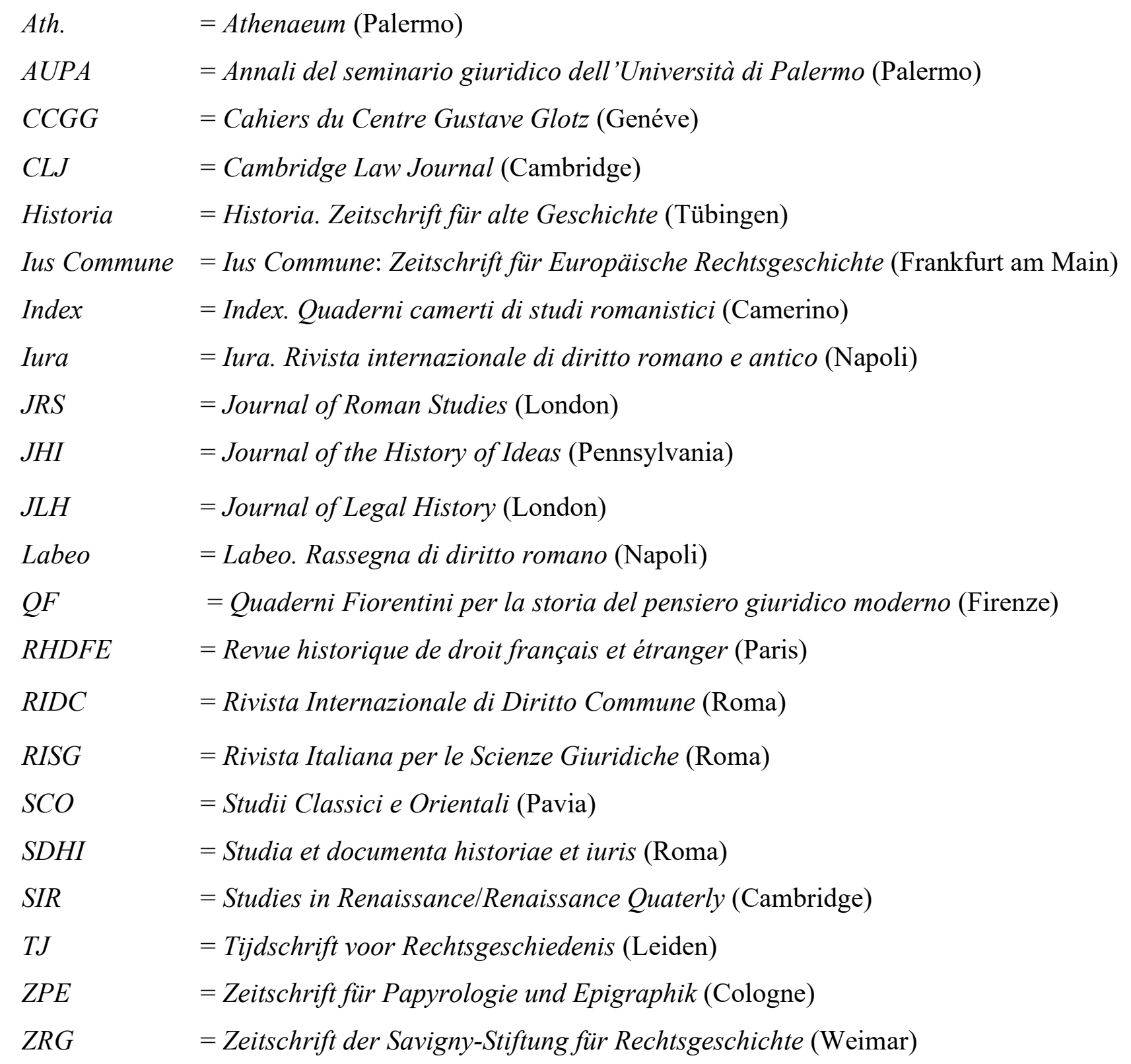




\section{INTRODUÇÃO}

In historia iuris universi pars optima latet

Jean Bodin

A iurisdictio se diz de muitos modos. Ou, ao menos, houve um tempo em que costumava se pensar assim.

Quando os juristas da Modernidade pensam a respeito de temas como a jurisdição, a administração e o acesso à justiça, consciente ou inconscientemente uma série de pressupostos da cultura jurídica e política moderna lhe preparam o palco. O primeiro deles é, sem dúvida, fornecido pelo paradigma da doutrina do Estado [Staatsrecht], uma das primogênitas do positivismo jurídico e da Pandectística novecentistas. Fruto de um apurado trabalho dogmático que pudesse dar corpo normativo às aspirações das filosofias do século XVIII e XIX, tal modo de conceber a comunidade política, a sujeição dos súditos ao soberano e a própria autoridade públicas permanece ainda um paradigma inconteste à despeito das inúmeras profecias sobre o fim do Estado, do Direito ou da História. Se o próprio Direito é entendido como um conjunto de normas, instituições e práticas dotadas de autoridade porque estão ligadas ao poder soberano, nada mais natural que o pensamento jurídico e filosófico moderno, desde Bodin, conceba também a jurisdição como uma prerrogativa do uso da força ou da coação.

Desejamos nessa pesquisa rumar para a direção oposta: se o tema da jurisdição parece hoje indissociável da figura monolítica de poder do Estado soberano - o Leviathan do frontispício da obra de Thomas Hobbes, aquele que porta ao mesmo tempo o cetro e a espada -, da bipartição entre Estado e sociedade e de monopólio vertical dos poderes decorrentes do exercício da jurisdição, isso não se dá como que por uma fatalidade natural, nem surgiu de um tubo de ensaio cósmico. Noutros tempos, culturas e sociedades, era possível conceber a atividade juridicente ${ }^{1}$ por outros meios e para outros fins. Movidos por essa constatação,

\footnotetext{
11 Utilizaremos a expressão juridicente para designar por meio do vernáculo aquilo que as fontes romanas apresentam quanto ao nosso objeto de análises. Embora tenham feito uso da palavra iurisdictio, -onis, já muito antes os romanos das atividades de administração do direito em termos de ius dicere (dizer com solenidade, ditar, dar autoridade ao direito), ius reddere (distribuir, aplicar, ministrar ou administra o direito), iuris dictum, iuris dicentis, ius dicentis officium. "Juridicente" foi a opção de tradução mobilizada por José Isaac Pilati em sua tradução e comentários ao título De Iurisdictione do Digesto de Justiniano (JoSÉ ISAAC PILATI, Digesto de Justiniano. Livro Segundo: Jurisdição. Florianópolis, editora da UFSC, 2013, p. 25, nota 1, na qual a opção de tradução é explicada e motivada pelo colóquio com Hélcio Maciel França Madeira, tradutor do livro primeiro do Digesto). Optamos pelo uso da expressão por muito bem-convir às de mantença da diacronia entre nossos conceitos e os conceitos do passado; e ainda, na complexa relação que se ocorrerá durante toda a pesquisa entre nossa própria linguagem, a linguagem histórica contida nas fontes, e os recorrentes processos de metalinguagem, de tradução e de elaboração de preceitos metodológicos que permitam alguma forma de acesso ao que os homens daqueles
} 
empreenderemos uma investigação de cunho histórico-jurídico que nos permita conhecer versões outras a respeito do direito e de sua aplicação.

Podemos circunscrever preliminarmente nosso objeto de pesquisa da seguinte forma: o que pensavam aqueles jurisconsultos que, situados na experiência jurídica romana, delineavam pela primeira vez na história do direito ocidental expressões com iurisdictio, ius dicere, ius reddere e ius dicentis? Se admitimos que foi na história do direito romano a primeira vez o exercício da jurisdição se tornou um objeto passível de apreensão cognoscitiva por aqueles juristas, como isso se deu? Tais indagações, de apelo já suficiente àqueles de índole mais curiosa, foram o motor condutor dessa pesquisa.

Expostos esses motivos, a tese tem por objetivo investigar a formação dos conceitos de iurisdictio, ius dicere e de suas expressões afins no bojo do pensamento jurídico entre a República e o Principado romanos. Para isso, partimos metodologicamente do pressuposto de que essas expressões constituíram na história da iurisprudentia romana como conceitos históricos básicos (Geschichtliche Grundbgriff), isso é que em algum momento puderam pôr em marcha a articulação de uma série de outros institutos e conceitos que diziam respeito à função jurisdicional.

Buscarmos atingir nossos objetivos, dividimos nossa pesquisa em duas grandes seções, materializadas nessa tese por suas duas partes.

Aa primeira parte da pesquisa histórica vai se voltar à história do pensamento jurídicocivilista entre a Baixa Idade Média e o primeiro despertar da cultura jurídica moderna no século XVI, dedicando a cada um desses dois períodos históricos um capítulo apartado. Embora possa ser um trajeto contraintuitivo - uma pesquisa histórica sobre Direito Romano que volta suas atenções também àqueles que sucederam à iurisprudentia no tempo -, temos razões para acreditar esse caminho reverso cumpre um papel fundamental ao nos colocar em contato não apenas com as fontes romanas, mas também com outros que, no passado, também pensaram e refletiram acerca do direito e de sua aplicação no mundo através do estudo das antigas disciplinas jurídicas dos romanos. É fortuito assinalar que nossas fontes de conhecimento para

tempos pensavam sobre a matéria. Desse modo, por regra, empregaremos sematncaiemtne os termos "jurisdicente", "funções" ou "atos juridicentes", "exercício juridicente", "magistrado juridicente", "prática juridicente" e outras variantes para nos referirmos ao nosso objeto de pesquisa, e os equivalentes modernos (jurisdição, jurisdicional etc.), em geral, para aludirmos aos fenômenos modernos. Mesmo que a comparação seja inescapável em História do Direito e mesmo que os pressupostos culturais do presente não possam ser depositados em gaveta na hora de praticarmos o ofício, pensamos que esse cuidado terminológico possa contribuir para a distinção entre os conceitos. 
a história da iurisdictio romana na segunda parte da tese basicamente são as mesmas utilizadas pelos juristas medievais entre os séculos XII e meados do século XV; e assim permaneceram nas mãos dos primeiros juristas modernos.

Assim sendo, dedicamos dois capítulos voltados à história da iurisdictio europeia: o primeiro situado entre os séculos do chamado renascimento jurídico de Bolonha, incluindo as doutrinas elaboradas por aqueles pensadores do medievo - os Glosadores e os Comentadores diante de suas próprias investigações a partir das fontes romana; ato contínuo, seguiremos o percurso até alcançarmos os primeiros críticos sistemáticos da teoria jurídica e da teoria de poder formulada pelos juristas medievais a partir da iurisdictio. Tais pensadores, basicamente aqui identificados como juristas que, na esteira do humanismo e do renascimento, propunham uma nova forma de analisar as funções públicas e a autoridade pública por meio do direito e de modo mais condizente com seu mundo. Um desses pensadores, não por acaso, foi justamente o jurista Jean Bodin, geralmente afinado como o pai da doutrina da soberania moderna. Como teremos oportunidade de demonstrar nesses capítulos, tanto os medievais quanto os modernos disputaram em torno do significado dos antigos textos do Digesto: a doutrina da soberania moderna foi um produto da chamada disputatio de iurisdictione.

O centro de nossa investigação a respeito da iurisdictio romana ocorre na segunda parte da tese. Uma vez cientes de como aqueles conceitos foram concebidos pelos modernos e pelos medievais - e dizendo muito mais a respeito dos próprios do que, diríamos, sobre os romanos mesmos -, com dois capítulos substanciais, cada um sob um diferente e complementar prisma. buscamos levar adiante nossas indagações a respeito da iurisdictio e de seu complexo semântico na história jurídica romana

No terceiro capítulo investigaremos o ius dicere romano a partir de sua história institucional, isso é, da história das instituições e autoridades publicadas, das magistraturas e, especialmente, das práticas jurídicas levadas à cabo por esses homens. Veremos que, no que toca ao aspecto institucional mais geral, ocorre uma mudança constitutiva e qualitativa (mesmo que não abrupta) entre a República e o Império. Se naquelao exercício das funções de dizer o direito estava espraiada por um mosaico quase sem fim de magistrados, poderes e diferentes e outras iurisdictiones (de fato, a iurisdictio se dizia de muitos modos), a partir do Principado, ao longo do reinado dos Antoninos e dos Severos a maior parte das instituições ligadas ao ius dicere e ao ius reddere são ressignificadas e conectadas ao princeps 
No último capítulo, tendo à nossa disposição as reflexões anteriores sobre a realidade fática e institucional da iurisdictio (e, de quebra, conhecidos os dois paradigmas epistemológicos anteriores, do medievo e da primeira modernidade, que buscaram explicar àquela realidade), buscaremos analisar aqueles conceitos na sua compleição de conceitos fundamentais, isso é, unidades semânticas que se constituíram ao longo do tempo e são rastreáveis no uso dos signos linguísticos das fontes, tornando possível a identificação das fontes clássicas e a empreitada para sua interpretação. 


\section{ÚLTIMAS CONSIDERAÇÕES}

Tanto na realidade institucional quanto no plano cognoscitivo e linguístico da jurisprudência romanas, é certo que tanto na República quanto no Império foram envergadas concepções bastante diversas das modernas a respeito do exercício da jurisdição, e igualmente são muito diversas das soluções interpretativas avocadas em outros tempos por Glosadores, Comentadores, bartolistas tardios e pelos humanistas-legistas franceses.

Os medievais conceberam a iurisdictio como o núcleo de uma teoria geral sobre as múltiplas esferas de ordenamento de sua sociedade: a função juridicente servia de paradigma, de genus generalissimum para a concepção mesma de poder entre os juristas da baixa Idade Média. Com a sua intrincada reflexão sobre as múltiplas e coetâneas iurisdictiones - a bela arbor iurisdictionis que adorna algumas das edições do Digestum Vetus no começo do Renascimento -, o pensamento jurídico de Azo, Cino, Bártolo e Baldo pôde utilizar-se dos fragmentos romanos para criar uma foram de explicar as diversas realidades normativas que conviviam e, por vezes, disputavam entre si.

Os humanistas, especialmente aqueles ligados ao humanismo jurídico francês do século XVI, ávidos por se livrarem da pesada herança medieval em sua cultura jurídica e explicarem em seus próprios termos as novas situações institucionais e jurídicas que na Europa acenavam para a subsequente formação dos primeiros Estados nacionais. Na pena de humanistas como Jean de Coras, Jean Tavard e Jean Bodin, a disputatio girou em torno da melhor interpretação histórica e jurídica para os poderes de iurisdictio, imperium mixtum, imperiium merum e a ascendente categoria de summa potestas (ou maiestas). Em sua maior parte textos hoje esquecidos (com a exceção óbvia dos livros sobre a República de Bodin, e que ainda assim, parecem ser antes objeto de citação do que de efetiva leitura), a discussão romanista de fundo nesses textos juridicentes foi a manjedoura sem a qual a teoria da soberania moderna, pelo menos como escrita por Bodin, não se poderia explicar.

O conceito de iurisdictio permitiu uma análise profunda e interdependente da linguagem jurídico-política (em suma, a prática e produção criativas, localizáveis em leis, institutos públicos e, naturalmente, na obra dos jurisconsultos) e da história institucional (em especial, mas não apenas, do ius publicum), duas facetas da História do Direito Romano. 
A história institucional e juspublicística de Roma, de suas magistraturas, ofícios e poderes, mesmo quando passada em rápidas tintas - não fizemos muito mais do que isso ao sumarizar as muitas autoridades juridicentes entre a República e o Principado - deixa claro que o exercício do poder juridicente em Roma, muito antes de se tornar um objeto de conceitualização (diríamos, antes do ius dicere se tornar iurisdictio), esteve ligada às necessidades institucionais de uma República em crescimento em expansão. A mudança para o Império não poderia passar despercebida: não porque o direito não fosse mais exercido, mas porque o era em diferentes termos e instâncias, subsumindo-se cada vez mais à autoridade do princeps.

Na linguagem institucional republicana, viu-se através das fontes, iuris dicere é um núcleo de prerrogativas dispostas pelo magistrado para que possa exercer de modo autônomo, pleno e eficiente a iurisdictio. Mesmo na época em que estivesse plenamente esvaziada de sentido essas antigas prerrogativas autônomas, juristas como Papiniano, Pompônio, Paulo e Gaio jamais deixaram de lado essa herança discursiva quanto ao ius dicere e ao ius reddere. Viu-se, porém, que foi especialmente no final do Principado, entre Septímio e Alexandre Severo, que os juristas da corte imperial se dedicaram de modo detido a um programa normativo um pouco mais estável e conhecido quanto às funções do juridicente. Ou melhor: quanto às funções delegadas. A iurisdictio mandata destrinçada por Ulpiano e Papiniano não era mero adorno de sua escrita sapiencial, mas um tema técnico que, se não chamasse atenções no período anterior, a partir dos Severos se torna a primeira disputatio de iurisdictione, a respeito não exatamente do conteúdo da iurisidictio ou as características do juridicente, mas dos limites e possibilidades de delegação.

Sem flutuar no vazio, a contribuição romana sobre o conceito de iurisdictio dos juristas da era dos Severos refletia as preocupações e transformações de um mundo. A civitas de Varro e Cícero deu lugar à construção do Principado e este, por sua vez, em finais do século II e princípios do século III exigiu do princeps uma engenharia institucional e jurídica que, sem abrir mão do poder político mais radical, mantivesse o tradicional e genuinamente romano esquema de repartição da administração imperial e provincial com as elites locais. Iurisdictio torna-se assim sinônimo de instrumento relevante para o equilíbrio entre o poder imperial e a complexa rede dos territórios influenciados por Roma. 


\section{REFERÊNCIAS BIBLIOGRÁFICAS}

$\underline{\text { Fontes primárias consultadas -autores/juristas medievais }}$

Alberico de Rosate, In primam Digesti Veteris partem Commentarii, Venetiis, 1585. Alberico de Rosate, Vocabularium utriusque iuris (= Dictionarium Alberici), Lugduni, 1548 .

Azo, Ad singulaes leges XII librorum Codicis Iustinianei commentarius et magnus apparatus [= Lectura], Lugduni, Iac. Stoer et Franc. Fab., 1596.

Azo, Summa Azonis Locuples Iuris Civilis Thesaurus [= Summa Codicis], Venetiis,1684.

Azo, Brocardica Aurea sive generalia iuris, Basileae, 1567.

Azo, Ad singulaes leges XII librorum Codicis Iustinianei commentarius et magnus apparatus [= Lectura], Lugduni, 1596.

Cino, Super Codice et Digesti Veteri Lectura, Lugduni, 1547.

Baldo, In primum, secundum et tertium Codicis libri commentaria, Venetiis, Iuntas, 1576.

Baldo, In quartum et quintum Codicis libros commentaria, Venetiis, Iuntas, 1577.

Baldo, In sextum Codicis Librum commentaria, Venetiis, Iuntas, 1586.

Baldo, Super VII, VIII, IX, X et XI Codicis libros commentaria, Venetiis, Iuntas, 1599.

Baldi, In primam Digesti Veteri partem commentaria, Venetiis, Iuntas, 1616.

Baldi, In secundam Digesti Veteri partem commentaria, Venetiis, Iuntas, 1616.

Baldo, In decretalium volumen commentaria, Venetiis, Iuntas, 1595.

Baldo, Consiliorum, sive responsorum [= Consilia], Venetiis,1575-80, 5 vol.

Bártolo, Consilia, quaestiones et Tractatus, Lugduni, 1552.

Bártolo, Distinctiones, Venetiis, F. Laurentini, 1564.

Bártolo, In primam Digesti Veteris partem, Venetiis, Iuntas, 1570.

Bártolo, In secundam Digesti Veteris partem, Venetiis, Lugduni, 1555.

Bártolo, In primam et secundam Digesti Veteris partem, Turin, 1577.

Bártolo, In primam et secundam Digesti Novi partem commentaria, Taurinorum, 1577.

Bártolo, In primam et secundam Infortiati partem, Venetiis, Iuntas, 1570.

Bártolo, In primam et secundam Codicis partem commentaria, 1577.

Bártolo, In tres Codicis libros commentaria, Augustae Taurinorum, H. N. Beuilaque, 1570.

Bártolo, De Regimine Civitatis in QUAGLIONI, DIEGO, Politica e diritto nel trecento italiano: il De tyranno di Bartolo da Sassoferrato, 1314-1357: con l'edizione critica dei trattati De guelphis et gebellinis, De regimine civitatis e De tyranno, Firenze. Olschki, 1983.

Butrigário (Jacob Butrigário), Lectura super Codicem, Paris, 1516.

Guilelmo de Cugno, Lectura super Codicem, Lugduni, 1513.

Gulielmo Durand, Speculum Iuris, Venetiis, Iunta, 1602, vol. 1.

Jácobo d'Arena, Commentarii in universium ius civile, Lugduni, A Porta, 1541.

Jacques de Revigny, Lectura Digesti Veteris, Lugduni, 1550.

Paulo Castrense, Commentaria super Digesto Veteri, Lugduni, 1538.

Piacentino, In Codicis Dn. Iustiniani sacr. princ. ex repet. praelectione libros IX Summa a Placentino legum interprete [= Summa Codicis] Moguntiae, 1536.

Pílio de Medicina, Tancredo de Bolonha, Grátio Aretino [Arezzo], Libri de iudiciorum ordine, Gottingae, ed. Fridericus Bergmann, Vandenhoeck et Ruprecht, 1842.

Rogério, Summa Codicis, in SAG, v. 1. 
$\underline{\text { Fontes primárias consultadas - autores/juristas modernos }}$

Alciato, Andrea, Opera, Ludguni, 1560, 4 vol.

Alciato, Andrea, In Digestorum Commentaria, Lugduni, 1560, 3 vol.

Alciato, Andrea, De Verborum significatine libri quatuor, Lugduni, 1562.

Alciato, Andrea, Lucubrationum in ius civile et pontificium, Basileae, 1571, 5 vol.

Barreto, Tobias, Estudos de Direito: Publicação Posthuma dirigida por Sylvio Roméro,

Rio de Janeiro, Laemmert, 1892.

Baro, Eguinarius. Variarum quaestionum publice tractarum ad Digesta iuris civilis: De

Iurisdictione, Lugduni, 1548.

Baro, Eguinarius. Commentarii ad 'ta prota' Digestorum quorum particula prior ius Romanum, posterior Gallicum, ad singulos titulos complectitur in Opera Omnia, vol. 1, Paris, 1562.

Baro, Eguinarius. Ad Omnes Partes Digestorum seu Pandectarum Iuris enucleati Manualium Libri Singulares, Coloniae 1580.

Bodin, Jean, Oratio de instituenda in repub. iuventute ad Senatum Popolumque Tolosatem, Tolosae, 1559.

Bodin, Jean, Methodus ad facilem historiarum cognitionem, $1^{\text {a }}$ ed., Paris, 1566.

Bodin, Jean, Methodus ad facilem historiarum cognitionem, $2^{\mathrm{a}}$ ed., Paris, 1572.

Bodin, Jean, Les six livres de la République, Paris, 1576 [ed. brasileira: Os Seis Livros da República, trad. José Ignacio Coelho Mendes Neto e José Carlos Orsi Morel, São Paulo, Ícone, 2011, 6 vols.].

Bodin, Jean, De Republica libri sex, Paris, 1586.

Bodin, Jean, I sei libri della Reppublica, ed. ital. trad. Lorenzo Cotti, Genova, 1588.

Bodin, Jean, Los seis libros de la Republica, ed. Esp. trad. Gaspar de Añastro Ysunza, Turin, 1590.

Bodin, Jean, The Six Books of Commonweale, trad. ing. Richard Knolles, London, 1606.

Bologneti, Giovanni, In eam Pandectarum partem quam Primam Digesti Veteris Commentariorum Pars Prima, Venetiis 1572.

Budée, Guillaume, Annotationes in XXIV libros Pandectarum, Paris, 1521.

Budée, Guillaume, De asse et partibus eius libri quinque, Paris, 1541.

Coras, Jean de, De Iurisdictione et imperio, in Miscellaneorum iuris civilis, Lugduni, 1549, 6 vol.

Coras, Jean de, In Primum Pandectarum librum, ac secundi titulum primum Commentarii, Lugduni, 1549.

Cujas (Cujácio), Jacques, Opera in tomos XIII distributa, Paris, 1891, 13 vols.

Domat, Jean, Les loix civiles dans leur ordre naturel, $2^{\circ}$ ed., Paris, 1697.

Doneau (Donello), Hugues, Commentariorum de jure civili in Opera Omnia, Florentia, 1847,12 vols.

Douaren (Duareno), François, Disputationes anniversariarum libri duo, Coloniae Agrippinae, 1573.

Douaren (Duareno), François, Omnia quae quidem hactenus extant opera, Lugduni 1579 .

Dumoulin (Du Moulin), Charles. Opera quae extant omnia, Paris, 1638, 3 vols.

Erasmo, Dialogus Ciceronianus sive de optimo genere dicendi, Lugduni, 1543 [ed. brasileira: Diálogo Ciceroniano, trad. Elaine Sartorelli, São Paulo, Unesp, 2013].

Gentili, Scipione, De iurisdictione libri III, Frankfurt, 1601. 
Gillot, Jean, De iurisdictio et imperio libri duo, Paris, 1570.

Hotman, François, Antitribonian, Paris, 1603.

Hotman, François, Francogallia, Frankfurt, 1586.

Hotman, François, Novus commentarius verbis iuris, Veneza, 1564.

Hotman, François, Observationum in ius civile libri IX, Geneva, 1589.

Godefroy, Denys, Statuta Regni Italiae iuxta Francorum, Burgundionum, Gothorum et Anglorum, Francofurti, I. Trevtelii, 1612.

Gouveia, Antônio de, De Iurisdictione Libri II, Tolosae, 1551.

Gouveia, Antônio de, Opera iuridica, filologica et philosophica, Roterodami, 1766.

Le Caron (Charondas), Louis, De iurisdictione et de imperio, Paris, 1554.

Le Caron (Charondas), Louis, Pandectes ou digestes du droit françois, Paris, 1637.

Longueval (Longovallius), Jean, Nova et facilis declaratio ad l. imperium ff. de iurisd.

omn. iud., Paris, 1528.

Longueval (Longovallius), Jean, Tractatus de imperio et iurisdictione, Coloniae

Agrippinae, 1591.

Loriot, Pierre, De iurisdictione et imperio, in De iuris apicibus tractatus VIII, Lugduni, 1555.

Menochio, Giacomo, Commentaria, Coloniae Agrippinae, 1572.

Montaigne, Michel de, Essais, $1^{\text {a }}$ ed. (livros 1-2), 1580 [ed. brasileira: Ensaios, trad. Sérgio

Millet, São Paulo, Ed. 34, 2016].

Musconius, Hieronymus, Tractatus de iurisdictione atque imperio, Coloniae, 1596.

Tavard, Jean, De iurisdictione et imperio, Tolosae, 1557.

Valla, Lorenzo, De elegantiarum latinae linguae libri sex, Lugduni, 1556.

Valla, Lorenzo, Opera, Basileae, 1540.

Zasius, Ulrich, Operum Omnium, Frankfurt, 1590. 
Bibliografia contemporânea

Adverse, Helton, A Matriz Italiana in Newton Bignotto (org.), Matrizes do Republicanismo, Belo Horizonte, Editora UFMG, 2013, p. 51-125.

Albanese, Bernardo, Il processo privato romano delle legis actiones, Palermo, G. B. Palumbo \& C., 1987.

Anderson, Perry, Linhagens do Estado Absolutista, $3^{\mathrm{a}}$ ed., trad. João Roberto Martins Filho, São Paulo, Brasiliense, 2004 [original: Lineages of the Absolutist State, London, NLB, 1974].

Auerbach, ERICH, A Novela no Início do Renascimento: Itália e França, trad. Tercio Redondo, São Paulo, Cosac, 2013 [original: Zur Technik der Frührenaissance-novelle in Italien und Frankreich, Heidelberg, C. Winter, 1921].

Azar Filho, Celso Martins, Humanismo, Antropologia e Filosofia, (manuscrito de conferência disponível na internet), 2010. Disponível em: http://www.ufrrj.br/graduacao/prodocencia/publicacoes/eticaalteridade/artigos/Celso_Azar.pdf. Acesso: 10/07/2019.

Barbati, Stefano, Ancora sulle cosiddette 'colonie latine fittizie transpadane'. Asc. In Pis. 3 Clark, in Quaderni Lupiensi di Storia e Diritto 49 (2013), p. 59-106.

Barros, Alberto Ribeiro G. de, A teoria da soberania de Jean Bodin, São Paulo, Unimarco/Fapesp, 2001.

BARros, Douglas Ferreira, Julgar a República: Método, soberania e crítica à liberdade no Methodus de Jean Bodin, Rio de Janeiro, Loyola-Discurso, 2012.

BASCHET, JÉRÔME, A civilização feudal: do ano mil à colonização da américa, trad. Marcelo Rede, São Paulo, Globo, 2006, p. 366-373 [original: La civilization féodale - de l'na mil à la colonization de l'Amerique, Paris, Flammarion, 2004].

BAUMAn, Richard A., Criminal Prosecutions by the aediles, in Latomus 33, f. 2 (1974), p. 263-264.

BAUMAN, RICHARD A., Lawyers in Roman Transitional Politics: A study of the Roman jurists in their political setting in the Late Republic and Triumvirate, München, C. H. Beck, 1985.

Bauman, Richard A., Lawyers and Politics in the Early Roman Empire: A study of relations between the Roman jurists and the Emperors from Augustus to Hadrian, München, C. H. Beck, 1989.

BECK, HANS, Consular power and the Roman constitution: the case of 'imperium' reconsidered, in H. BECK; A. DuPlá; M. JEHNE; F. PINA POLO, Consuls and res publica: Holding High Office in the Roman Republic, Cambridge, CUP, 2011, p. 75-96.

Beggio, Tommaso, 'Per legem Aebutiam et duas Iulias sublatae sunt istae legis actiones': alcune considerazioni sull 'evoluzione dei 'iudicia legitima' a partire dalla 'lex Aebutia' in GAROFALO, LUIGI (a cura di), Il giudice privato nel processo civile romano: omaggio ad Alberto Burdese, t. 3, Padova, CEDAM, 2015, p. 85-140. 
BENERT, RICHARD Roy, Inferior Magistrates in Sixteenth-Century Political and Legal Thought, Thesis (Doctor of Philosophy), University of Minnesota, 1967. Disponível em: < https://conservancy.umn.edu/handle/11299/160022 >. Acesso: 19/08/2019.

Benveniste, ÉMILE, O Vocabulário das Instituições Indo-Européias, 2 vols., trad. Denise Bottmann, Campinas, UNICAMP, 1995, vol. II, p. 9-15 [= original: Le vocabulaire des institutions indo-européennes, vol. I: économie parenté, societé, vol. II: pouvoir, droit, religion, Paris, Minuit,1969].

Berger, Adolf, Encyclopedic Dictionary of Roman Law, Philadelphia, The American Philosophical Society, 2004 [1 $1^{\text {a }}$ ed. 1953],

Berman, Harold J., Direito e Revolução: a formação da tradição jurídica ocidental, São Leopoldo, Unisinos, 2006 [original: Law and Revolution: the Formation of the Western Legal Tradition, New York, Harvard, 1983.

BISCARDI, ARNALDO, Lezioni sul processo romano antico e classico, Torino, Giappichelli, 1967.

BLACK, RoBERT, The Origins of Humanism, in MAZzOCO, ANGELO (ed.), Interpretations of Renaissance Humanism, London, Brill, 2006, p. 37-72.

Blockmans, Wim e HopPenbrouwers, Peter, Introdução à Europa Medieval: 300-1550, Rio de Janeiro, Forense/GEN, 2012. [original Eeuwen des Onderscheids: een Geschiedenis van Middeleeuws Europa, Amsterdam, Bert Bakker, 2002]

BÖCKenförde, ERnst-WolfGang, História da Filosofia do Direito e do Estado: Antiguidade e Idade Média, trad. Adriana Beckman Meirelles, Porto Alegre, Fabris, 2012 [original: Geschichte der Rechts- und Staatsphilosophie: Antike und Mittelalter, Tübingen, Mohr Siebeck, 2002].

Böttcher, Carlos AleXandre, História da Magistratura: O Pretor no Direito Romano, São Paulo, LCTE, 2011

Brennan, T. C. [Terry CoRey], The Praetorship in the Roman Republic, 2 vol., Oxford, OUP, 2000.

BREMER, FRAZ PETER, Iurisprudentiae Antehadrianae quae supersunt, 2 vol. Leipzig, B. G. Teubner, 1896.

Bretone, Mario, Tecniche e ideologie del giuristi romani, $2^{\mathrm{a}}$ ed., Napoli, Ed. Scientifiche Italiane, $1982\left(1^{\mathrm{a}}\right.$ ed. 1971).

Brunt, P. A. [Peter Ahsbury], Italian Manpower: 225 B.C. - A.D. 14, Oxford, Clarendon, 1971.

Brunt, P. A. [Peter Ahsbury], Lex de imperio Vespasiani, in JRS 67 (1977), p. 95-116.

BRUTti, MASSIMO, Il dialogo tra giuristi e imperatori, in MAROTTA, VALERIO - STOLFI, EMANUElle (a cura di), in Ius Controversum e processo fra tarda Repubblica ed età dei Severi: Atti del Convegno (Firenze, 21-23 ottobre 2010), Roma, L'Erma di Bretschneider, 2012, p. 97-204.

Calasso, Francesco, Medio evo del Diritto: I. Le Fonti, Milano, Giuffrè, 1954. 
CAlASSO, FRANCESCO, I Glossatori e la teoria della sovranità: studi di diritto comune pubblico, $3^{\mathrm{a}}$ ed., Milano, Giuffrè, 1957.

CALASSO, FRANCESCO Il diritto comune come fatto spirituale in RISG 6 (2015), p. 3-40 (orig. CAlasso, F., Introduzione al diritto comune, Milano, Giuffrè, 1951, p. 137-180).

Cannata, Carlo Augusto, Profilo istituzionale del processo privato romano, 2 vol., Torino, Giappichelli, 1980-1982.

CAnning, Joseph, The Political Thought of Baldus de Ubaldis, (1 ${ }^{\mathrm{a}}$ ed. 1987), Cambridge, CUP, 2003.

CApogrossi Colognesi, Luigi, Storia di Roma tra diritto e potere, $2^{\mathrm{a}}$ ed., Bologna, il Mulino, 2014 [1 ${ }^{\mathrm{a}}$ ed. 2009].

CAPPEllini, PaOlo, Dal diritto romano al diritto privato moderno, in Aldo Schiavone (a cura di), Diritto privato romano: um profilo storico, Einaudi, 2002, p. 453-474.

CARPINTERO, FrANCISCO, 'Mos italicus', 'mos gallicus' y el Humanismo racionalista. Una contribución a la historia de la metodología jurídica, in Ius Commune 6 (1977), Frankfurt am Main, Vittorio Klostermann, p. 108-171.

Carvalho, Frank Viana, O Pensamento Político Monarcômaco: da limitação do poder real ao contratualismo, Tese (Doutorado em Filosofia), Faculdade de Filosofia, Letras e Ciências Humanas, Universidade de São Paulo, 2007.

CAScione, Cosimo, Tresviri capitales: storia di una magistratura minore, Napoli, Scientifica, 1999.

CAVANna, AdRIANo, Storia del diritto in Europa: le fonti e il pensiero giuridico, vol. I (Il pensiero giuridico), Milano, 1982.

Chauvire, Roger, Jean Bodin: auteur de la "République », Paris, Ancienne Honoré Champion, 1914.

Church, William Farr, Constitutional Thought in Sixteenth-Century France: A Study in the Evolution of Ideas, New York, Octagon 1969.

CORNELl, T. J. [Timothy], The Beginnings of Rome: Italy and Rome from the Bronze Age to the Punic Wars (c. 1000-264 BC), London, Routledge, 1995.

Correia, Alexandre; Correia, AleXandre Augusto; Sciascia, Gaetano, Manual de Direito Romano Vol. 2: Institutas de Gaio e de Justiniano vertidas para o português, em confronto com o texto latino, $2^{\mathrm{a}}$ ed., São Paulo, Saraiva, 1955.

Costa, Marta Nunes Da, Origens do Conceito de soberania: diálogo entre Bodin e Althusius, in Filosofia Moderna Contemporânea v. 2, n. 2 (2014), p. 70-79.

Costa, PIETRo, Semantica e storia del pensiero giuridico. QF 1 (1972), Milano, Giuffrè, vol. 1, 1972, p. 45-87.

COSTA, PIETRO, Iurisdictio: semantica del potere politico nella reppublica medievale (11001433), $2^{a}$ ed., Milano, Giuffrè, 2002 [1 $1^{\mathrm{a}}$ ed. Milano, Giuffrè, 1969].

COSTA, PIETRo, Soberania, representação, democracia: ensaios de história do pensamento jurídico, trad. Alexander Rodrigues de Castro, Angela Couto Machado Fonseca, Érica 
Hartman, Ricardo Marcelo Fonseca, Ricardo Sontag, Sergio Said Staut Jr., Walter Guandalini Jr., Curitiba, Juruá, 2010.

Crawford, Michael H. (ed.), Roman Statutes, 2 vols., London, Institutes of Classical Studies, 1996 (Bulletin of the Institute of Classical Studies Supplement n. 34).

Crawford, Michael H., How to create a 'municipium': Rome and Italy after the social war, in Modus Operandi 42, Supp. 71 (1998), p. 153-161.

CRESCENZI, Victor, Per una semantica della necessitas in alcuni testi giuridici di ius commune, in MAZZON, ANTONELla (a cura di), Scritti per Isa: Raccolta di studi offerti a Isa Lori Sanfilippo, Sassoferrato, Istituto Storico Italiano per il Medio Evo, 2008, p. 263-290.

CRESCENZI, ViCTOR, Bartolo da Sassoferrato e il problema del potere pubblico, in CRESCENZI, Victor e Rossi, GiovanNi (a cura di), Bartolo da Sassoferrato nella cultura europea tra Medioevo e Rinascimento, Istituto internazionale di Studi Piceni "Bartolo da Sassoferrato", 2015, p. 97-118.

Cruz e Tucci, José Rogério - Azevedo, luiz Carlos, Lições de História do Processo Civil Romano, São Paulo, RT, 1996.

CRUZ E TUCCI, JosÉ RoGÉRIO, Jurisdição e poder: contribuição para a história dos recursos cíveis, São Paulo, Saraiva, 1987.

DAl Ri JR., ARno e Nunes, Diego, A tirania como categoria jurídica de governo: a construção do ius publicum medieval na obra de Bartolo de Saxoferato, Revista Justiça Do Direito 32, 3 (2019), p. 480-508.

DAUBe, DAVID, The Peregrine Praetor, in JRS 41 (1951),

Di PAOLI, AlESSANDRO, Lorenzo Valla ovvero la filosofia della politica nel Rinascimento, Roma, F. Bocca, 1872, p. 7-33.

D'ORS, ÁlVARO - D'ORS, JAVIER [= XAVIER], Lex Irnitana: edición bilíngue, in Cuadernos Compostelanos de derecho romano 1 (1988), Santiago de Compostela, Imprensa da Univ. de Santiago de Compostela.

DRUMMOND, ANDREW, Rome in the fifth century II: the citizen community, in ASTIN, A Frederickesen, M. W. - Ogilvie, R. M. - WAlbANK, F. W. (eds.), The Cambridge Ancient History. Vol. 7, part 2, the rise of Rome to 220 BBC, $2^{\mathrm{a}}$ ed., Cambridge, CUP, 1990.

Du Plessis, Paul J., Towards the Medieval Law of Hypothec, in CAIRns, JoHn W. e Du Plessis, PAUl J. (eds.), The Creation of Ius Commune: from casus to regula, Edimburgh, Edimburgh University Press, 2010.

ECK, WERNER, L'Italia nell'Impero Romano. Stato e amministrazione in epoca imperiale, trad. Klaus Fabian - Silvia Strassi, Bari, EdiPuglia, 1999 [original: Die Staatliche Organisation Italiens in der hohen Kaiserzeit, München, C. H. Beck, 1979],

ECK, WERnER, The growth of administrative posts, in BOWMAN, A. K.; GARNSEY, PETER; Rathbone, Dominic (eds.), The Cambridge Ancient History, Vol. 11: the High Empire, A.D. $70-192,2^{a}$ ed., Cambridge: CUP, 2000, p. 238-265.

Elias, Norbert, O Processo Civilizador, trad. Ruy Jungmann, Rio de Janeiro, Zahar, 1993, 2 vol. [original Über den Prozess der Zivilisation, Basileia, Falken, 1939]. 
Fasolt, Constantin, The Limits of History, Chicago, Chicago University Press, 2004.

FASsò, GuIDO, Storia della filosofia del diritto: 1. Antichità e medioevo, Bari, Laterza, 2001.

FANIZZA, LUCIA, L'Amministrazione della giustizia nel Principato: aspetti, problemi, Roma, L'Erma di Bretschneider, 1999.

FAORO, DAVIDE (a cura di) et al, L'amministrazione dell'Italia romana: dal I secolo a.C. al III secolo d.C., fondamenti, Firenze, Le Monier, 2018.

FARIA, ERnesto, Gramática Superior da Língua Latina, Rio de Janeiro, Livraria Acadêmica, 1958.

Fell, Armand London, The Classical Four Causes in the Renaissance Art of Law: Legislation, Sovereignity, and the State in Marsilius of Padua, Corasius and Bodin, Thesis (Doctor of Philosophy), Faculty of Political Science, Columbia University, 1973.

Fioravanti, Maurizio, Stato e costituzione, in M. FIORAVANTI (org.), Lo Stato moderno in Europa: instituzioni e diritto, Laterza, 2002

FlorenZANo, Modesto, Notas sobre tradição e ruptura no Renascimento e na primeira Modernidade, in Rev. Hist. 135 (1996), p. 19-30.

ForCellini, EgIDIO Totius Latinitatis Lexicon, 1688-1768, t. II, p. 113-115, v. dico; t. II, p. 969-970, v. jus; t. II, p. 228-229; t. II, p. 204-206, v. duco; t. II, p. 203, v. edico e v. edictum (e também disponível on-line no Digital Forcellini Project: < http://linguax.com/lexica/forc2.php >. Acesso: 07/01/2020

FrIER, Bruce W., The Rise of the Roman Jurists: Studies in Cicero's "Pro Caecina", Princeton, PUP, 1985.

GABBA, EMILIO, Rome and Italy in the second century B.C. in ASTIN, A. E.; FREDERICKSEN, M. W.; Ogilvie, R. B.; Walbank, F. W. (eds.), The Cambridge Ancient History. Vol 8: Rome and the Mediterranean to 133 BC, $2^{\mathrm{a}}$ ed., Cambridge, CUP, 1989.

GAGLIARDI, LORENZO, I collegi giudicanti: 'decenviri', 'centumviri', 'septemviri', 'recuperatores'. Idee vecchie e nuove su origini, competenze, aspetti procedurali, in GAROFALO, LUIGI (a cura di), Il giudice privato nel processo civile romano: omaggio ad Alberto Burdese, t. 2, Padova, CEDAM, 2012, p. 341-383.

Gargola, Daniel J., The Shape of the Roman Order: The Republic and Its Spaces, Chapel Hill, The University of North Carolina Press, 2017.

GeElHAAR, Clemens, Some remarks on the lex de provinciis praetoriis, in Revue internationale des droits de l'Antiquité 49 (2002), p. 109-118.

GILLI, PATRICK, Cidades e Sociedades Urbanas na Itália Medieval: séculos XII-XIV, trad. Marcelo Cândido da Silva e Victor Sobreira, Campinas, UNICAMP, 2011 [orig. Villes et sociétés urbaines em Italie: milieu XII ${ }^{e}$-milieu XIV siècle, Paris, Armand Colin, 2005].

GiLmore, MYron P., The World of Humanism: 1453-1517, New York, Harper, 1952.

GILMORE, MYron P., The Jurisprudence of Humanism, in Traditio 17 (1961), p. 493-501.

Gilmore, Myron P., Argument from Roman Law in political thought, 1200-1600, $3^{\text {a }}$ ed., New York, Russell \& Russell, 1967 [1 ${ }^{\text {a }}$ ed. 1941]. 
GiLson, Étienne, A Filosofia na Idade Média, trad. Eduardo Brandão, São Paulo, Martins Fontes, 2001. [original: La Philosophie au Moyen Áge, Paris, Payot, 1986].

GIRARD, P. F. [PAUl FREDERIC], Histoire de l'organisation judiciaire des romains, Paris, Arthur Rousseau, 1901.

Graevius, Johannes Georgius [Graef, Johan GeORG], Thesaurum Antiquitatum Romanarum et Historiarum Italia, Leiden, Pieter van der A., 1704-1725, 9 vol.

GrandaZZI, AleXANDre, As Origens de Roma, trad. Christiane Gradvohl Colas, São Paulo, UNESP, 2010, p. 166 (orig. Les Origines de Roma, Paris, Presses Univ. de France, 2003).

Grendler, Paul F., Humanism: Ancient Learning, Criticism, Schools and Universities, in MAZzoco, ANGelo (ed.), Interpretations of Renaissance Humanism, London, Brill, 2006, p. 73-96.

Grossi, PaOlo, Un diritto senza Stato (la nozione di autonomia come fondamento della costituzione giuridica medievale), in QF 25 (1996), Milano, Giuffrè, p. 267-284. [trad. port. Um Direito sem Estado: a noção de autonomia como fundamento da constituição medieval, trad. Felipe Pante Lemos de Campos, in Revista Jurídica da Presidência v. 1, n. 123 (2019), p. 20-41.

Grossi, PaOlo, L'Ordine Giuridico medievale, $8^{\mathrm{a}}$ ed., Roma-Bari, Laterza, 2001 [trad. port. A Ordem Jurídica Medieval, São Paulo, WMF Martins Fontes, 2014].

Grossi, PaOlo, Mitologias jurídicas da modernidade, $2^{\mathrm{a}}$ ed., trad. Arno Dal Ri Júnior, Florianópolis, FUNJAB, 2007 [original: Mitologie giuridiche della modernità, Milano, Giffrè, 2001].

Grossi, PaOlo, O Direito entre poder e ordenamento, trad. Arno Dal Ri Júnior, Belo Horizonte, Del Rey, 2010.

Guarino, Antonio, Salvius Iulianus: Profilo biobibliografico, Catania, G. Crisafulli, 1946.

Guarino, Antonio, L'esegesi delle fonti del diritto romano (a cura di Luigia Labruna), Napoli, 1968.

Guarino, Antonio, Storia del Diritto Romano, 8a ed., Napoli, Jovene, 1990.

GuARINO, ANTONIO, La leggenda sulla codificazione dell'editto e la sua genesi, in Pagine di diritto Romano, vol. IV, Napoli, Giovene, 1994, p. 253-266 [orig. 1951].

Guarino, Antonio, La pretesa codificazione dell'editto, in Pagine di diritto Romano, vol. IV, Napoli, Giovene, 1994, p. 218-252 [orig. 1953].

Guarino, Antonio, Gaio e l' "Edictum Provinciale”, in Pagine di diritto Romano, vol. IV, Napoli, Giovene, 1994, p. 279-295 [orig. 1969].

Otto Reitzius, Gullielmus - NAnNis, Petrus - De Corte, JacQues - Thol, Pieter VAN - Thol, Отtho van, Theofilou Antikensoros Ta heuriskomena. Theophili Antecessoris Paraphrasis Graeca Institutionum Cesarearum, Den Haag [Haia], apud Fratres Ottonem et Petrum Thollius, 1751.

Haskins, CHARLes Homes, The Renaissance of the Twelfth Century, New York, HUP, 1927. 
Hallebeek, Jan, Structure of Medieval Roman Law in PihlaJAmäKi, HeIKKI - DubBer, MARKUS e GODFREY, MARK, The Oxford European Legal History, Oxford, OUP, 2018, p. 286-308.

Harries, JiLl Diana. Cicero and the Jurists: From Citizens' Law to the Lawful State, London, Duckworth, 2006.

Hassal, Mark - Crawford, Michael H. - Reynolds, Joyce, Rome and the Eastern Provinces at the End of the Second Century B.C., in JRS 64 (1974), p. 192-220.

Hespanha, ANTÒnio MANUEl, Cultura Jurídica Europeia: síntese de um milénio, Coimbra, Almedina, 2012.

Honoré, Anthony Maurice [= Tony Honoré], Gaius. A Biography, Oxford, Clarendon, 1962-a.

HONORÉ, TONy, The Severan Lawyers. A Preliminary Survey, in SDHI (1962-b), p. 162-232.

Honoré, TONY, Word Frequencies and the Study of Roman Law, in CLJ 30.2 (1972), p. 280-293.

HonORÉ, TONY, Tribonian, Ithaca, Cornell UP, 1978.

HonOrÉ, Tony, Ulpian: Pioneer of Human Rights, $2^{\mathrm{a}}$ ed., Oxford, OUP, 2002 (1 $^{\mathrm{a}}$ ed. 1982).

HONORÉ, TONY, Emperors and Lawyers with a Palingenesia of Third-Century Imperial Rescripts 193-305 AD, 2a ed., Oxford, OUP, 1994 (1 ${ }^{\mathrm{a}}$ ed. London, 1981).

Jones, A. H. M. (ARNOLd Hugh MARTin), Studies in Roman Government and Law, Oxford, Blackwell, 1960.

Jesús Vallejo [Jesús Vallejo de La Riguiera], Power Hierarchies in Medieval Juridical Thought: An Essay in Reintrepretation, in Ius Commune 19 (1992), Frankfurt am Main: Vittorio Klostermann.

KANTOROWICZ, HERMANN, The poetical sermon of a mediaeval jurist, Journal of the Warburg Institute, v. 2, n. 1 (jul.1938), p. 22-41.

Kantorowicz, ERnst H. z, The King Two Bodies: A Study in Mediaeval Political Theology, 7a ed., Princeton, Princeton University Press, 1997.

KASER, MAX, Römische Rechtsgeschichte, $2^{\mathrm{a}}$ ed., Göttingen, Vandenhoeck \& Ruprecht, 1967 (trad. ital. Storia del Diritto Romano, trad. Remo Martini, Milano, Cisalpino, 1977).

KASER, MAX -HACKL, KARL, Das römische Zivilprozessrecht, 4ª ed., C. H. Beck, 1996.

KNAPP, P. C., Festus 262L and praefecturae in Italy, Pavia, in Ath. 58.1 (1980), p. 14-38.

Kelley, Donald R., François Baudouin and his Conception of History, in JHI 25.1 (1964), p. 35-57.

Kelley, Donald R., Legal Humanism and the Sense of History, in SIR 72.13 (1966), p. 184-199.

Kelley, Donald R., Budé and the First Historical School of Law, in The American Historical Review 72, n. 3 (1967), p. 807-834. 
Kelly, J. M. [John Maurice], Studies in the Civil Judicature of the Roman Republic, Oxford, Clarendon, 1976.

Keohane, Nannerl O., Philosophy and the State in France: The Renaissance to the Enlightment, New Jersey, Princeton University Press, 1980.

KISCH, GUIDO, Humanistic Jurisprudence, in SIR 72.8 (1961), p. 71-87.

Koselleck, ReINHART, Crítica e Crise: uma contribuição à patogênese do mundo burguês, trad. Luciana Villa-Boas Castelo-Branco, Rio de Janeiro, EdUERJ-Contraponto, 1999 [original: Kritik und Krise: Ein Beitrag zur Pathogenese der bürgerlichen Welt, München, Verlag, 1959].

Kunkel, Wolfgang, Historia del Derecho Romano, trad. Juna Miquel, Barcelona, Ariel, 1966 (original: Römische Rechtsgeschichte. Eine Einführung, 4ª ed., Köln-Graz, Böhlau, 1964 [1 $1^{\text {a }}$ ed. 1952]).

LAFFI, UMBERTO, Rome e le province, $1^{o}$ tomo: organizzazzione, economia, società, in Bologna, Cappelli, 1985 (col. Storia di Roma, vol. XVII).

LAFFI, UMBERTO, Di nuovo sulla datazione del fragmentum Atestinum, in Ath. 78 (1990), p. 167-175.

LAFFI, UMBERTO, 'Modus operandi' in margine ad um'interpretazione del 'fragmentum Atestinum', in Studi Classici e Orientali 46, n. 1 (1998), p. 153-161.

LAFFI, UMBERTo, Studi di storia romana e di diritto, Roma, Edizioni di Storia e Letteratura, 2001.

LAMBERTI, FRANCESCA, "Tabulae Irnitanae”: municipalità e "ius romanorum”, Napoli, Eugenio Jovene, 1993.

LEE, DANIEL, Popular Sovereignty in Early Modern Constitutional Thought, Oxford, OUP, 2016.

Le Goff, JACQUes, Os Intelectuais na Idade Média, $3^{\mathrm{a}}$ ed., trad. Marcos de Castro, Rio de Janeiro, José Olympio, 2010 [orig. Les Intellectuels au Moyen Ages, Paris, Seuil, 1957].

LEIFER, FrAnZ, Die Einheit des Gewaltgedankens im römischen Staatsrecht, München, Duncker \& Humboldt, 1914.

Отто Lenel, Das Edictum Perpetuum: Ein Versuch zu seiner Wiederherstellung, 3 bd., Leipzig, Bernhard Tauchnitz, 1927 [1 bd. 1883].

Lintott, ANDREw, Notes on the Roman Law Inscribed at Delphi and Cnidos, in ZPE 20 (1976), p. 65-82.

Lintott, Andrew, The Constitution of the Roman Republic, Oxford, Clarendon, 1999.

Lloyd, Howell A., Sovereignity: Bodin, Hobbes, Rousseau in Revue Internationale de Philosophie, v. 45, n. 179 (1991), p. 353-379.

Lloyd, Howell A. (ed.), The Reception of Bodin, Leiden/Oxford, Brill, 2013.

Lloyd, Howell A., Jean Bodin, 'This Pre-eminent Man of France': An Intellectual Biography, Oxford, Oxford University Press, 2017. 
LoUREnÇO, Frederico, Nova Gramática do Latim, Lisboa, Quetzal, 2019.

Luhmann, Niklas, Teoria dos Sistemas na Prática: vol. I, Estrutura social e semântica, trad. Patrícia Silvia Santos, Petrópolis, Vozes, 2018 [original: Gesellschaftsstruktur und Semantik: Studien zur Wissenssoziologie der modernen Gesellschaft, Suhrkamp, 1980].

Madeira HÉlcio Maciel FrançA, História da Advocacia: Origens da profissão de advogado no Direito Romano, São Paulo, RT, 2002.

MAFFeI, DOMENICO, Gli inizi dell'umanesimo giuridico, $3^{\mathrm{a}}$ ed., Milano, Giuffrè, 1972 [1 ${ }^{\mathrm{a}} \mathrm{ed}$. 1956].

Maitland, Frederic William (ed.), Preface, in Years Books of Edward II, Vol. I: 1 \& 2 Edward A.D. 1307-1309, London, 1903.

Magalhães, Juliana Neuenschwander, Formação do Conceito de Soberania: História de um Paradoxo, São Paulo, Saraiva, 2016.

MAGANZANI, LAURETTA, Juridiction romaine et autonomie locale dans les provinces au dernier siècle de la République, in RHDFE 85.3 (2007), p. 353-373.

Malavolta, Mariano, Sulla clausola discrezionale della c.v. lex de imperio Vespasiani, in Simblos 5 (2008), p. 15-129.

MANNORI, LUCA, Per una 'preistoria' della funzione amministrativa: cultura giuridica e attività dei pubblici apparati nell'età del tardo diritto comune, in QF 19 (1990), Milano, Giuffrè, p. 323-504.

MANTOVANI, DARIO, Les clauses 'sans précédents' de la Lex de imperio Vespasiani: Une interprétation juridique, in CCGG 16 (2005), p. 25-43.

Mantovani, DARIO, Lex 'regia' de imperio Vespasiani. Il 'vagum imperium' e la legge costante, in L. CAPOGROSSI COLOGNESI - ElENA TASSI SCANDONE (a cura di), La Lex de Imperio Vespasiani e la Roma dei Flavi (Atti del Convegno, 20-22 novembre 2008), Roma, L'Erma di Bretschneider, 2009-b, p. 125-155.

MANTOVANI, DARIO, “Quaerere”, “quaestio”. Inchiesta lessicale e semantica, in Index 37 (2009), Napoli, Jovene, p. 25-67.

MARChi, EdUARDo C. SilveIRA, A "Garota de Ancio" e o instituto jurídico do tesouro, in Estudos de Direito Civil: a garota de Âncio, a Nua Propriedade, a Causa Curiana e o Soneto de Fidelidade, São Paulo, Saraiva, 2013.

MARENBON, JoHn, Logic before 1100: the latin tradition, in Dov. M. GABBAY e JoHN Woods (ed.), Handbook of the History of Logic: Mediaeval and Renaissance Logic, 2008, p. 1-64.

MaRTINO, FRANCESCo DE, La giurisdizione nel diritto romano, Padova, CEDAM, 1937.

MARTINO, FrAnCESCO DE, Storia della costituzione romana, $2^{\mathrm{a}}$ ed., Napoli, Jovene, 19721975 [1 $1^{\text {a }}$ ed. 1951-1972].

MCNeIL David O., Guillaume Budé and Humanism in the Reign of Francis I, Genève, Droz, 1975. 
Mesnard, PIERRE, Jean Bodin a Toulouse in Bibliothèque d'Humanisme et Renaissance, vol. 12.1 (1950), p. 31-59.

Mesnard, Pierre, La Filosofia Política en el Siglo XVI, trad. desc. Guatemala, Universidade de Puerto Rico, 1956 [original L'essor de la philosophie au XVIe siècle, Paris, Boivin, 1936].

Mesnard, PiERre, Jean Bodin en la Historia del Pensamiento, Madrid, Instituto de Estudios Politicos, 1962.

METZGER, ERnEST, Agree to Disagree: Local Jurisdiction in the Lex Irnitana, in BuRrows, A. - Johnston, D. - Zimmermann, R. (eds.), Judge and Jurist: Essays in Memoir of Lorde Rodger of Earlsferry, Oxford, OUP, 2013, p. 207-225.

Miglietti, SARA, Tra pubblico e privato. Osservazioni sul pensiero etico e politico di Jean Bodin, Tesi di laurea specialistica (Filosofia e forme del sapere), Università di Pisa, 2008. Disponível em: < https://etd.adm.unipi.it/t/etd-06102008-184954/ >. Acesso: 16/05/2019.

Miglietti, SARA, Introduzioni in Bodin, JeAn Methodus ad Facilem Historiarum Cognitionem. Ed. Sara Miglietti, Pisa, Edizioni della Normale, 2013, p. 5-58.

MireILle, CORBIER, Les circonscriptions judiciaires de l'Italie de Marc-Aurèle à Aurélien, in Mélanges de l'École française de Rome, Antiquité, t. 85, n. 2 (1973).

Mommsen, TheOdor, Abriss des römischen Staatsrechts, Leipzig, Verlag, 1893 (trad. ital. Disegno de Diritto Pubblico Romano, trad. Pietro Bonfante, Milano, Francesco Vallardi, 1893).

Mommsen, Theodor, Römisches Strafrecht, Leipzig, Von Ducker \& Humblot, 1899 (trad. esp. Derecho Penal Romano, $2^{\text {a }}$ ed., trad. Pedro Dorado Montero, Madrid, Temis, 1999).

Moraes, Bernardo Bissoto Queiroz de, Manual de Introdução ao Digesto, São Paulo, YK, 2017.

Mousourakis, GeORge, A Legal History of Rome, New York, Routledge, 2007.

NÖRR, DIETER, Pomponio o 'della intelligenza storica dei giuristi romani'. Con una 'nota di lettura' di Aldo Schiavone, a cura di Michele Antonio Fino ed Emanuele Stolfi, in Rivista di Diritto Romano 2 (2002), p. 167-254.

Nunes, Silvio Gabriel Serrano, As Origens do Constitucionalismo Calvinista e o Direito de Resistência: a legalidade bíblica do profeta em John Konx e o contratualismo secular do jurista em Theodóre de Bèze, Tese (Doutorado em Filosofia), Faculdade de Filosofia, Letras e Ciências Humanas, Universidade de São Paulo, 2017.

ORESTANO, RICCARDO, L'appello civile in diritto romano: corso di diritto romano, $2^{\mathrm{a}}$ ed., Torino, Giappichelli, 1966 [ $1^{\circ}$ ed. 1953].

ORESTANO, RICCARDO, Introduzione allo studio storico del diritto romano, 2. ed., Bologna, Il Mulino, 1961.

ORESTANO, RiCCARDO, Il 'problema delle persone giuridiche' in Diritto Romano, Torino, Giappichelli, 1968 
OSLer, Douglas J., Humanist Philology and the Text of Justinian's Digest, in Du Plessis, PAUl J. e CAIRnS, John W., Reassessing Legal Humanism and its Claims: Petere Fontes?, Edinburgh, Edinburgh University Press, 2016, p. 41-56.

Overfield, James H., Humanism and Scholasticism in Late Medieval Germany, New Jersey, Princeton University Press, 1984.

Pagnin, Beniamino, La 'littera Bononiensis': studio paleografio, in Ricerche Medievale, 10-12 (1975-1977), p. 93-168. Disponível em Monumenta Germinae Historica: < http://www.mgh.de/ >. Acesso: 30.01.2019.

Palazzolo, Nicolla, Processo Civile e politica giudiziaria nel Principato: lezioni di diritto romano, $2^{\mathrm{a}}$ ed., Torino, Giappichelli, 1991 [1 $1^{\mathrm{a}}$ ed. 1980].

PAlmer, Robert E. A., The Archaic Community of the Romans, Oxford, CUP, 1970.

M. PAni, L'imperium de Principe, in CAPOgRossi Colognesi, L. - SCANDONE, E. T. (a cura di), La Lex de Imperio Vespasiani e la Roma dei Flavi (Atti del Convegno, 20-22 novembre 2008), Roma, L’Erma di Bretschneider, 2009.

PANI, MARIO, Il costituzionalismo di Roma antica, Roma, Laterza, 2010.

PAIS, ETTORE, Ricerche sulla storia e sul diritto pubblico di Roma, vol. I, Roma, Loescher, 1915.

Peck, Harry Thurston, A History of Classical Philology: From the Seventh Century B.C. to the Twentieth Century A.D., New York, Macmillan Co., 1911.

Penguilly, Thomas, Le juriste et le philologue. Enjeux et formes des rivalités entre André Alciat et Guillaume Budé à travers leurs correspondances, in GAVOILLE, ELISABETH UILlAUMONT, FRANÇOIS (eds.), Conflits et polemiques dans l'épistolaire, Paris, Tours, 2015, p. $468-483$.

Pennington, Kenneth, Lotharius of Cremona, in Bulletin of Medieval Canon Law 20 (1990), p. 43-50.

Pennington, Kenneth, Odofredus and Irnerius, in RIDC 28 (2017), p. 43-50.

PiAnO MoRTARI, VINCENZO, Il potere sovrano nella dottrina giuridica del secolo XVI, Napoli, Liguori, 1973.

PiAno Mortari, Vincenzo, Cinquecento giuridico francese: lineamenti generali, Napoli, Liguori, 1990.

Pilati, José IsAac, Propriedade e Função Social na Pós-Modernidade, $2^{\mathrm{a}}$ ed., Rio de Janeiro, Lumen Juris, 2012.

Pilati, José IsaAc, Digesto de Justiniano. Livro Segundo: Jurisdição, Florianópolis, FUNJAB/EdUFSC, 2013.

Pina Polo, Francisco - Fernández, Alejandro DíAz, The Quaestorship in the Roman Republic, Berlin, De Gruyter, 2019.

PozzoBon, AlBeRto, Le regulae iuris e la ricostruzione del diritto per principi: il paradigma canonistico del Tractatus de regulis iuris (1733) di A. Reiffenstuel, Tesi (Dottorato di ricerca) - Università degli Studi di Padova, Padova, 2013. 
Pugliese, Giovanni, Il processo civile Romano: I, le legis actiones, Roma, Ricerche, 1962.

Quine, Willard Van Orman, Dois Dogmas do Empirismo, in De um Ponto de Vista Lógico, trad. Antonio Ianni Segatto, São Paulo, UNESP, 2011. [Original: From a logic point of view: 9 logical-philosophical essays, Harvard, Harvard University Press, 1953].

RAMOS, FeliPe De FARIAS, A modernidade jurídica e o jusnaturalismo moderno: a superação da experiência medieval e a constituição de um novo paradigma, in Captura Criptica (4), 1, jan./dez. 2013, p. 241-257.

RIBAS-AlBA, JosÉ MARIA, La Lex Irnitana: Estructura Politica y aspectos jurisdiccionales, in Estudios de derecho romano e historia del derecho comparado: trabajos en homenaje a Ferran Vals I Taberner, Málaga, Univ. de Málaga, 1991, p. 5419-5455.

Richardson, John S., Roman provincial administration: 227 BC to AD 117, London, Bristol Classical Press, 2001.

Riscal, SANDRA APARECIDA, O conceito de Soberania em Jean Bodin: um estudo do desenvolvimento das ideias de administração pública, governo e Estado no século XVI, Tese (Doutorado em Educação), Faculdade de Educação, Universidade Estadual de Campinas, 2018. Disponível em: < http://www.repositorio.unicamp.br/handle/REPOSIP/251407 >. Acesso: 15/06/2019.

Robles, JuAn RAMón, Magistrados, Jueces y Árbitros en Roma: Competencia civil y evolución, Madrid, Dykinson, 2019.

RodGer, ALAN, Jurisdictional Limits in the Lex Irnitana and the Lex de Gallia Cisalpina, in ZPE 110 (1996), p. 189-206.

Roldán, Miguel del Pino, Nueva traducción de la Lex Flavia Malacitana, in Mainake 23 (2001), p. 51-70.

Rosa, Alberto Asor, Storia europea della letteratura italiana: I. Le origini e il Rinascimento, Turim, Einaudi, 2009.

Rosa, AlBerto Dalla, Ductu auspicioque: per una riflessione sui fundamenti religiosi del potere magistratuale fino all'epoca augustea, in SCO 49 (2003),

Rossi, Giovanni, Valla e il diritto: L'epistola contra Bartolum e le Elegantiae. Percorsi di ricerca e proposte interpretative, in REGOLIOSI, MARIANGELA (a cura di), Pubblicare il Valla, Firenze, Polistampa, 2008, p. 507-599.

Rossi, Giovanni, François Hotman vs. Triboniano: una critica radicale al diritto romano nella Francia del XVI secolo, in QF 44 (2015), t. 1, Milano, Giuffrè, p. 253-299.

Rossi, Giovanni, Valla e il Diritto; L'Epistola contra Bartolum e le Elegantiae. Percorsi di cerca e proposte interpretative, in REGOLIOSI, MARIANGELA (a cura di), Pubblicare il Vallai, Firenze, Polistampa, 2008, p. 507-599.

Rossi, Giovanni, Letture umanistiche del Digesto lungo il XV secolo: Da Valla a Poliziano, in MANTOVANI, DARIO - PADOA SCHIOPPA, , Interpretare il Digesto: storia e metodi, Pavia, CEDANT, 2014, p. 311-370. 
Rossi, Giovanni, La lezione metodologica di Andrea Alciato: filologia, storia e diritto nei 'Parerga', in Rollet, ANNE e Rollet, ShÉPANe (eds.), Andrea Alciat (1492-1550): un humaniste au confluent des savoirs dans l'Europe de la Renaissance, Turnhout Brepols, 2013, p. 145-164.

Rossi, GuIDO, Deconstructing Iurisdictio: The Adventures of a Legal Category in the Hands of the Humanist Jurists, in Du Plessis, PAUl J. e CAIRnS, JoHn W., Reassessing Legal Humanism and its Claims: Petere Fontes?, Edinburgh, Edinburgh University Press, 2016, p. 59-87.

RUDORFF, AUGUST FREDERICK, De iuris dictione edictum. Edicti perpetui quae reliqua sunt, Leizpig, apud Hirzelium, 1869.

Santalucia, Bernardo, Diritto e processo penale nell'antica Roma, $2^{\mathrm{a}}$ ed., Milano, Giuffrè, 1998 [1 ${ }^{\mathrm{a}}$ ed. 1989].

SAntalucia, Bernardo, Studi di diritto penale romano, Roma, L'Erma di Bretschneider, 1994.

SAntalucia, Bernardo, La giustizia penale in Roma antica, Bologna, il Mulino, 2013.

SANCHI, Luigi-Alberto, Guillaume Budé et la lengue juridique in RHDFE 93.4 (2015), p. 487-501.

SAnChi, Luigi-Alberto, Per la ricezione di Poliziano in Francia: spunti dall'opera erudita di Guillaume Budé, in Archivum Mentis 3 (2014), p. 233-246.

SANDYs, John Edwin, A History of Classical Scholarship, vol. II: From the Revival of Learning to the End of the Eighteenth Century (in Italy, France, England, and the Netherlands), Cambridge, CUP, 1908.

SAVIGNY, FRIEDRICH CARL VON, Geschichte des römischen Rechts im Mittelalter, Heidelberg Mohr, 1815-1831, 7 vol.

Schiavone, Aldo (a cura di), Storia giuridica di Roma, Torino, Giappichelli, 2016.

Schiavone, Aldo, Ius: l'invenzione del diritto in Occidente, $2^{\mathrm{a}}$ ed. Roma, Giulio Einaudi, 2017 [ $1^{\text {a }}$ ed. 2005].

Schioppa, Antonio PadoA, História do direito na Europa: da Idade Média à Idade Contemporânea, trad. Marcos Marcionilo, São Paulo, WMF Martins Fontes, 2014 [original: Storia del diritto in Europa, Bologna, Il Mulino, 2007].

SCHULZ, FRITZ, History of Roman Legal Science, Oxford, OUP, 1946.

SKINNER, QUENTIN, Fundações do pensamento político moderno, São Paulo, Cia das Letras, 1996 [original: The Foundations of the Modern Political Thought, 2 vols. Cambridge, CUP, 1978].

Scialoja, VitTorio, Procedimiento Civil Romano: ejercicio y defensa de los derechos, trad. Santiago Sentis Melendo - Marino Ayerra Redin, Buenos Aires, Europa-America, 1954 [original: Procedura civile romana, Roma, F. illi Pallotta, 1894]. 
SEnEllart, Michel, As Artes de Governar: do regimen medieval ao conceito de governo, trad. Paulo Neves, São Paulo, Ed. 34, 2006 [original Les artes de gouverner, Paris, Ed. Seuil, 1995].

Serrao, Feliciano, La “iurisdictio” del pretore peregrino, Milano, Giuffré, 1954.

SERRAO, Feliciano, Il modello di costituzione, in A. SChIAVONE (a cura di), Storia giuridica di Roma, Torino, Giappichelli, 2016.

SiSANI, SimONE, istituzioni municipali: legislazione e prassi tra il I secolo a.C. e l'età flavia, in CAPOgrossi ColONESI, L. - Lo CASCIO, E. - TASSI SCANDONE, E (a cura di), L'Italia dei Flavi. Atti del Convegno, 4-5 ottobre 2012, Roma, L'Erma di Bretschneider, 2016, p. 9-55.

SiSANI, SIMONE, Le magistrature locali delle comunità municipali di ambito provinciale: uno studio sulla diffusione del quattuorvirato e del duovirato tra l'età tardo-reppublicana e l'età imperiale, in Gerión 36.1 (2018), p. 41-77.

Smith, C. J. [Christopher John], The Roman Clan: The Gens from Ancient Ideology to Modern Anthropology, Cambridge, CUP, 2006.

Stein, Peter, Roman Law in European History, Cambridge, CUP, 1999.

Stolfi, EMAnUele, I segni di una tecnica. Alcune considerazioni attorno a rigore terminologico e lessico delle citazioni nella scrittura dei giuristi romani, in AUPA 59 (2016), p. 113-149.

Steel, CAtherine, The Lex Pompeia de provinciis of 52 B.C.: A Reconsideration, in Historia 61.1 (2012), p. 83-93.

Straumann, Benjamin, Crisis and Constitutionalism: Roman Political Thought from the Fall of the Republic to the Age of Revolution, New York, OUP, 2016.

Syme, Ronald, Three Jurists, in Roman Papers: edited by Anthony R. Birley, Oxford, Clarendon, 1979-1991, 7 vols., vol. II, p. 790-804.

Syme, RonALD, Lawyers in Government: the case of Ulpian, in Roman Papers: edited by Anthony R. Birley, Oxford, Clarendon, 1979-1991, 7 vols., vol. III, p. 863-868.

TeIXeIRA, FeliPe Charbel, Timoneiros: retórica, prudência e história em Maquiavel e Guicciardini, Campinas, Unicamp, 2010.

TIERNEY, BRIAN, Religion, Law and the growth of constitutional thought, 1150-1650, Cambridge, CUP, 1982.

TORRENT, ARMANDO, La 'iurisdictio' de los magistrados municipales, Salamanca, Gráficas Europa, 1970

Tuck, Richard, Jean Bodin in The Sleeping Sovereign: The Invention of Modern Democracy, Oxford, OUP, 2016, p. 1-62.

TuORI, KaIUS, Hadrian's Perpetual Edict: Ancient Sources and Modern Ideals in the Making of a Historical Tradition, in JHL 27.3 (2006), p. 219-237.

TUORI, KAIUS, The Emperor of Law: The Emergence of Roma Imperial Adjudication, Oxford, OUP, 2016. 
Ullmann, Walter, Law and Politics in the Middle Ages: an introduction to the sources of medieval political ideas, New York, CUP, 1975.

Ullmann, Walter, Medieval Foundations of Renaissance Humanism, Ithaca, Cornell University Press, 1977.

USSANI, VINCENZO SCARANO, L'ars dei giuristi: considerazioni sullo statuto epistemologico della giurisprudenza romana, Torino, Giappichelli, 1997.

VV.AA, Monumenta Germaniae Historica [MGH], München, Bayerische Staatsbibliotek, das Deutsche Institut für Erfoschung des Mittelalters, 1826-. Inteiramente disponível em: < http://www.mgh.de/ >. Acesso: 10.03.2019.

VAsconcellos, Manoel da Cunha lopes [= Conselheiro VASCONCEllos]; Marchi, Eduardo C. Da Silveira; Moraes, Bernardo B. QueIroz de; RODRIGUES, Dárcio R. Martins; MAdeira, Hélcio Maciel FrançA, Digesto ou Pandectas do Imperador Justiniano, São Paulo, YK, 2017-, 3 vol.

VALDITARA, GiUSEPPE, Lo stato nella storia nell'antica Roma, Rubbetino, 2008

VIEHWEG, THEODOR, Tópica e Jurisprudência: uma contribuição à investigação dos fundamentos jurídico científicos, $5^{\mathrm{a}}$ ed., trad. Kelly Susane Alflen da Silva, Porto Alegre, Sergio Antonio Fabris, 2009 [original: Topik und Jurisprudenz: ein Beitrag zur rechtswissenschaftlichen Grundlagenforschung, 5a ed., München, C.H. Beck, 1974.

VILlEy, Michel, A formação do pensamento jurídico moderno, trad. Claudia Berliner, São Paulo, Martins Fontes, 2005 [original: La Formation de la pensée juridique moderne, Paris, PUF, 1975].

VINCENTI, UMBERTO, La costituzione di Roma antica, Bari, Laterza, 2017.

VINCENTI, UMBERTO, Ius publicum: storia e fortuna delle istituzioni pubbliche di Roma antica, Napoli, Jovene, 2018.

Vinogradoff, Paul, Roman Law in Medieval Europe, s.l., Ampere Publishing, 2015 (1 ${ }^{\mathrm{a}}$ ed. 1909, Oxford, Harper \& Brothers).

WIEACKer, Franz, História do Direito Privado Moderno, trad. Antònio Manuel Hespanha, 4. ed. Lisboa, Calouste Gulbenkian, 2010 [original: Privatrechtsgeschichte der Neuzeit unter besonderer Berücksichtigung der deutschen Entwicklung, Göttingen, Ruprecht].

WiLKS, IAn, Peter Abelard and his Contemporaries, in Dov. M. GaBbay e John Woods (ed.), Handbook of the History of Logic: Mediaeval and Renaissance Logic, 2008, p. 83153.

WlassaK, MORITZ, Römische Prozessgesetze. Ein Beitrag zur Geschichte des Formularverfahrens, 2 vol., Leipzig, Duncker \& Humblot, 1888-1891. 


\section{ÍNDICE DE FONTES}

\section{I) FonTES JURÍDICAS}

\section{I.A) FONTES JURÍDICAS PRÉ-JUSTINIANEIAS}

\section{LEX XII TABULARAM (LEI DAS XII TÁBUAS)}

XII Tab. 1.1, p. 240

XII Tab. 1.8, p. 238

XII Tab. 1.9, p.238

XII Tab. 9.1-2, p. 231, p. 250

XII Tab. 3.1-6, p. 240

\section{LEGES}

Fragmentum Atestinum (= FIRA I, $20=R S$ I, 16), p. 262

Lex Acilia repetundarum, (= FIRA I, $\left.7=R S \mathrm{I}, 1=C I L \mathrm{i}^{2}, 583\right)$, p. 219, 245, 253, 289, 292

Lex Agraria [Baebia], (= FIRA I, $8=R S$ I, $2=C I L$ i $\left.^{2}, 585\right)$, p. 236, 292, 294

Lex Antonia de Termessibus (FIRA I, $11=\mathrm{RS}$ I, $19=\mathrm{CIL} \mathrm{i}^{2}$ ). p. 266, 294

Lex coloniae Genetivae Iuliae = Lex Urson. (= FIRA I, $21=R S$ I, 25), p. 263, 296, 349

Lex Cornelia de XX quaestoribus, (= FIRA I, 10), p. 251

Lex de piratis persequendis, (= FIRA I, $9=R S$ I, 12), p. 225

Lex Iulia agraria = Lex Mamilia Roscia Peducaea Alliena Fabia, (= FIRA I, 12), p. 295

Lex Latina tabulae Bantinae, (= FIRA I, 6), p. 253

Lex Malacitana, (= FIRA I, 24), p. 309-310

Lex Rubria de Gallia Cisalpina (= FIRA I, 19), p. 260, 262, 301

Lex Papiria de sacramentis, (= FIRA I, $2=R S$ II, 45), p. 256, 236, 289

Lex Plaetoria de iurisdictione, (= FIRA I, $3=R S$ II, 44)

Lex Salpensana, (= FIRA I, 23 = CIL II, 253), p. 309, 349

Tab Heracleensis $=$ Lex Iulia municipalis, (= FIRA I, $13=$ RS I, $24=$ CIL i², 593), p. 257, 298

\section{SENATUSCONSULTA}

SC. De Bacchanalibus, p. 235

\section{GAI INSTITUTIONES}

Gai. 1.1, p. 333

Gai. 1.2 , p. 341

Gai. 1.5 , p. 361

Gai. 1.6, p. 341

Gai. 1.98, p. 234

Gai. 1.99, p. 234

Gai. 1.101, p. 234

Gai. 1.109, p. 342

Gai. 1.112, p. 201

Gai. 2.24, p. 238 
Gai. 2.101, p. 101

Gai. 3.155-162,

Gai. 3.160, p. 361

Gai. 3.161, p. 361

Gai. 3.162., p. 361

Gai. 4.11, p. 239, 240, 242, 342

Gai. 4.16, p. 276

Gai. 4.21 , p. 240

Gai. 4.29 , p. 240

Gai. 4.30 , p. 240

Gai. 4.31, p. 255

Gai. 4.39-44, p. 441

Gai. 4.11-29. p240

Gai. 4.72 , p. 342

Gai. 4.76 , p. 342

Gai. 4.104, p. 246, p. 267, 268, 290

Gai. 4.105 , p. 255

Gai. 4.110, p. 342

Gai. 4.111, p. 342

Gai. 4.118 , p. 342

Gai. 4.138, p. 242

Collatio

Coll. 1.2 [Paul. 5 sent.], p. 226

Coll. 1.3 [Ulp. 7. de off. proc.] (= FIRA II, p. 544-545), p. 226

VATICANA FRAGMENTA

Vat. Frag. 197-198, p. 267

Vat. Frag. 173-211, p. 276

Vat. Frag. 232, p. 280

\section{I.B) FONTES JUSTINIANEIAS}

\section{CORPUS IURIS CIVILIS}

INSTITUTIONES
I. 1.2 .5 , p. 3.6 .1
I. 1.2 .7 , p. 305 .
I. 1.2 .58 , p. 305
I. 2.1 .39 , p. 11
I. 2.23 .1 , p. 276
I. 2.25 pr., p. 276
I. 3.26 , p. 361

\section{DIGESTA}

D. 1.1.7.1, p. 343

D. 1.1 .8 , p. 343

D. 1.1 .11 , p. 343

D. 1.2.2.2pr., p. 341

D. 1.2 .2 .5 , p. 359

D. 1.2 .2 .9 , p. 340 
D. 1.2 .2 .10 , p. 339

D. 1.2 .2 .12 , p. 339

D. 1.2 .2 .13 , p. 341

D. 1.2 .2 .19$, p. 279

D. 1.2 .2 .22 , p. 194

D. 1.2 .2 .27 , p. 339,341

D. 1.2 .2 .28 , p. 340

D. 1.2 .2 .30$. , p. 253

D. 1.2 .2 .32 p. $340-341$

D. 1.2 .2 .33 , p. 340

D. 1.2 .2 .34 , p. 340

D. 1.2 .2 .43 , p. 343

D. 1.2 .2 .44 , p. 335

D. 1.3 .12 , p. 347

D. 1.3 .13 , p. 343

D. 1.3 .321$, p. 53

D. 1.3 .32 , p. 52,360

D. 1.3 .33 , p. 360

D. 1.3 .34 . p. 360

D. 1.3 .37 , p. 360

D. 1.10.1.1., p. 278

D. $1.11 .1 \mathrm{pr}, \mathrm{p} .278$

D. 1.11.2., p. 278

D. 1.18 .11 , p. 283

D. 1.18 .12 , p. 283

D. 1.18 .14 , p. 283

D. 1.18 .17 , p. 283

D. 1.18.19pr., p. 283

D. 1.18 .19 .1 p. 283

D. 1.18 .21 , p. 283

D. 1.19.1pr., p. 367

D. 1.19 .1 .1$, p. 280

D. 1.19 .1 .2 , p. 280 .

D. 1.21.1pr., p. 282,356

D. 1.21.1.1., p. 282,356

D. 1.21 .3 , p. 282,253

D. 2.1 .1 , p. 361

D. 2.1 .3 , p. $38,41,42,49,54,57,237,362$

D. 2.1 .5 , p. 350,360

D. 2.1 .6$, p. 360,3688

D. 2.1 .7 , p. 336

D. 2.1 .10 , p. 365 , p. 361

D. 2.1.11pr., p. 344

D. 2.1.11.2., p. 344

D. 2.1 .16 , p. $358,362,363,366,368$

D. 2.1.17. p. $358,362,363,366,368$

D. 2.2 .3 pr., p. 196 , p. 217

D. 2.4 .18 , p. 187

D. 2.15 .8 pr., P. 357

D. 2.15 .8 .18 . p. 217

D. 3.4 .6 .3 , , p. 358

D. 4.2 .9 .3 , p. 358

D. 4.4.16pr. p. 358

D. 4.8 .7 pr. p. 358

D. 5.1.2.1. p. 361

D. $12.59-60$. p. 361

D. 21.1.1.2., p. 361

D. 22.3 .5 pr., p. 357

D. 34.1 .3 , p. 383

D. 40.5 .41 .5 . p. 361 

D. 41.2.3.23.p. 361
D. 46.3 .88 . p. 357
D. 47.2.57.1. p. 357
D. $48.5 .16(15) .6$, p. 357
D. 48.14 .1 .4 . p. 357
D.48.19.41, p. 357
D. 49.1 .1 , p. 270,272
D. 49.1.4pr., p. 270,272
D. 49.1.5., p. 272
D. 49.1 .7 , p. 272
D. 49.1.14. ,p. 272
D. 49.1 .23 pr. p. 270,272
D. 49.1.26. p. 270, D 49.3.1pr., p. 372
D. 49.2 .1 .4 , p. 273
D. 49.2 .7 , p. 293
D. 49.1 .14 , p. 283
D. 49.1 .26 , p. 283
D. 49.14 .22 pr-3, p. 280 , p. 283
D. 49.14 .50 , p. 280
D. 49.15 .24 , p. 98
D. 50.13 .1 pr, p. 284,348
D. 50.13 .1 .1 , p. 348
D. 50.13 .1 .5 , p. 348
D. 50.13 .1 .6 , p. 348
D. $50.13 .1 .12 .-13$, p. 358
D. 50.16 .18 , p. 258
D. 50.16 .157 .1$, p. 330
D. 50.16 .228 , p. 345
D. 50.16 .293 .2 , p. 345
D. 50.16 .239 .7 , p. 333

\section{CODEX}
C. 1.14, p. 44,50
C. 1.14 .12 pr, p. 74
C. 1.14 .12 .3 , p. 52
C. 1.14 .14 , p. 47,73
C. 1.17 .1 .6$, p. 52
C. 4.56 .1 , p. 276
C. 6.54 .1$, p. 276
C. 7.37 .3 , p. 23

\section{I.C) Fontes Pós-JUstinianeias}

TEOPHILO

Paraph. 1.2.7, n. 58, p. 305

\section{II) FONTES EPIGRÁfICAS}

$C I L \mathrm{i}^{2}, 583=$ FIRA I, $7=R S$ I, 1, p. 219, p. 289,

$C I L \mathrm{i}^{2}, 585=$ FIRA I, $8=R S$ I, 2, p. 292, P. 294

$C I L \mathrm{i}^{2}, 589=$ FIRA I, $11=R S$ I, 19, p. 294 
$C I L \mathrm{i}^{2}, 592=$ FIRA I, $19=R S$ I, 28, P. 245-246, 206, 262, 304

$C I L \mathrm{i}^{2}, 593=$ FIRA I, $13=R S$ I, 24, p. 236, 245, 302, 309, 312

CIL II, 253=FIRA I, 23, p. 309

\section{III) FONTES LITERÁRIAS}

\section{Augustus}

Aug. Res Gestae, 6.1, p. 155

Aug. Res Gestae, 27.1, p. 284

Aug. Res Gestae, 6.21, p. 267

\section{CAesar (CAESAR Julius CAESAR)}

Bell. civ. 3.20.1-2, p. 320

Bell. gall. 6.23.5, p. 327

Bell. gall. 8.4.2, p. 327

Bell. gall. 8.23.3, p. 327

\section{CATO}

Agri. 149.2, p. 262

\section{CENSORINUS}

De die nat. 24.3, p. 216, 289

\section{Cicero (MARCus Tullius Cicero)}

Acad. 2.30.97, p. 270.

Acad. Prior. $2.144-144$, p. 38

Att. 4.2.3, p. 202

Att. 5.14.2, p. 321

Att. 6.2.5, p. 321

Brut. 106, p. 219, 226

Brut. 117, p. 253

Brut. 151, p. 343

Caec. 32-40, p. 423

Caec. 33 , p. 255

Caec. 66, p. 324

Caec. 76 , p. 324

Caec. 77 , p. 324

Cael. 21, p. 366.

Clu. 38, p. 253.

Clu. 39, p. 253.

Clu. 91 p. 352.

Clu. 148,p. 225.

Clu 141, p. 226

Clu. 147, p. 226

Clu. 148, p. 226

Corn. Sull. 37-38.

de Or. 1.173, p. 323.

de Or. 1.174-181, p. 255 
de Or. 1.188 , p. 324

de Or. 2.165, p. 229

de Or. 2.56, p. 359

Div. 2.42, p. 201

Dom. 29., p. 255

Dom. 71, p. 202

Dom. 130, p. 202

Dom. 136. p. 202

Fam. 1.1.22. p. 265.

Fam. 2.13.3, p.321, p. 367

Fam. 9.8.1. p. 359.

Fam. 12.23.3. p. 223.

Fam. 13.14.1, p. 327

Fam. 14.6.7. p. 265.

Inv. 2.78, p. 226.

Inv. 2.79 , p. 225

Leg. agr. 2.26-27. p. 323

Leg. 1.3.10.p. 270

Leg. 2.2.5. p. 263

Leg. 2.19, p. 201

Leg. 2.20, p. 201

Leg. 3.3.6, p. 253

Leg. 3.4.10, p. 206.

Leg. 2.3. p. 342

Leg. 3.5, p. 342

Leg. 3.6. p. 342

Leg. 3.7. p. 342

Leg. 3.8, p. 229

Leg. 3.10, p. 230, 233

Leg. 3.27. p. 233,

Leg. 33.10.

Mil. 78, p. 361.

Mur. 12. p240.

Mur. 13. p. 95.

Mur. 14. p. 95.

Mur. 15. p. 95.

Nat. deor. 3.7.

Off. 1.25.85.

Quinc. 7.29.

Quinc. 20.63-65.

Quinc. 26. p. 323

Rep. 1.39. p. 12, 101, p. 159

Rep. 1.41. p. 333

Rhet. ad Her. 2.13.19

Verr. 2.1.157-158, p. 270

Verr. 2.1.103, p. 270

Verr. 2.1.108, p. 270.

Verr. 2.2.39, p. 291

Verr. 2.3.63, p. 291

Verr. 2.3.74p. 291

\section{DIONYSIOS HALICARNASENSIS}

Dion. Halic. Ant. rom. 2.14, p. 184.

Dion. Halic. Ant. rom. 2.14.1-2.

Dion. Halic. Ant. rom. 3.61.2, p. 185. 
Dion. Halic. Ant. rom. 5.63-69, p. 209.

Dion. Halic. Ant. rom. 6.2., p. 196.

Dion. Halic. Ant. rom. 7.26.3, p 248

\section{FESTUS}

De verborum significatu (ed. Lindsay)

Fest. 36L, v. conventus, p. 333.

Fest. 42L v. Curia, p. 201.

Fest. 47L, v. centumviralia iudicia, p. 256

Fest. 74L, v. Forum, p. 244.

Fest. 113L, v. maximus pontifex, p. 200.

Fest. 121L, v. maior magistratus, P. 228.

Fest. 126L, v. municeps, p. 258.

Fest. 148L, v. minora, P.212

Fest. 152L, v. maximum praetorem.

Fest. 155L, v. municipiu, P. 212.

Fest. 165L, v. nefasti dies, p. 236

Fest. 176L, v. nundinas, p. 258.

Fest. 177L, v. nundinas, p.258.

Fest. 198L, v. ordo sacerdotum, p. 199.

Fest. 200L, v. ordo sacerdotum, p. 199.

Fest. 247L. v parrici(d) quaestores, p. 194.

Fest. 262L, v. Praefecturae, p. 258, 349

Fest. 310L, v. quaestores, p. 195.

Fest. 313L, v. quaeso, p. 195.

Fest. 342L, v. reciperatio, p. 256

Fest. 468L, v. sacramentum, p. 252, 289

Fest. 475L, v. sex Vestae sacerdotes, p. 201.

Fest. 516L, v. vindex, p. 236

\section{FRONTINUS}

De aquae. 2.129, p. 227.

De aquae. 97.3-4. p. 227.

De aquae. 97.9, p. 227.

De aquae. 9.3-4 p. 227.

De aquae.103-118 p. 227.

De aquae. 129.5.9-11, p. 227.

Strat. 4.5 , p. 329.

\section{Gellius (Aulus Gellius)}

Gel. 3.3.15.

Gel. 5.19, p. 201.

Gel. 16.10.8, p. 221.

Gel. 16.5.3, p. 330 .

Gel. 20.10.9, p. 319. 


\section{Historia Augusta}

H. A. Hadr. 18.1, p. 353

H. A. Marc. Aur. 10.2, p. 353

H. A. Marc. Aur. 11.6-10, p. 353

H. A. Marc. Aur. 12. 4, p. 353

H. A. Marci, 10., p. 353

H. A. Carac. $8.1-2$, p. 353

\section{ISIDORUS}

Isid. Ety. 5.3.1, p. 13

Isid. Ety. 11.6.28, p. 67.

\section{LIDO (JOHANN LYDOS; JOÃO, O LIDO)}

Lido, Mag. 1.27 , p. 251

Lido, Mag. 1.38, p. 212

Lido, Mag. 1.39, p. 212

Lido, Mag. 1.45, p. 217

\section{LIVIUS (TITUS LIVIUS)}

Liv. 1.8.2-3. P. 319.

Liv. 1.20. p. 194.

Liv. 1.24. p. 319.

Liv. 1.26. p. 319.

Liv. 1.27. p. 194.

Liv. 2.2.10-11.

Liv. 2.5. Liv. 2. 23. p. 194.

Liv. 3.43.3. p. 194.

Liv. 3.9.6. p. 194.

Liv. 3.55.7

Liv 6.20.11-12

Liv. 6.27.10. p. 288.

Liv. 6.34-35. p. 251

Liv. 6.34-42. p. 251

Liv. 6.35.-42. p. 251

Liv. 6.38.4-9. p. 251

Liv. 22.35.7. p. 328

Liv. 22.57.3. p. 328

Liv. 23.16-18. p. 328

Liv. 23.21 .2 p. 328

Liv. 23.30 .5 p. 328

Liv. 23.30 .18 p. 328

Lív. 23.32.2-4 p. 328

Liv. 23.30 .5 p. 328

Liv. 23.30 .18 p. 328

Lív. 23.32.2-4 p. 328

Liv. 24.44.2. p. 328

Liv. 24.10 .3 p. 328

Liv. 26.3 .9 p. 328

Liv. 26.16.10-16.

Liv. 27.22.3. p. 328

Liv. $27.23 .5-7$ p. 328

Liv. 28.10 .9 p. 328

Liv. 28.11.6; p. 328 
Liv. 29.20.4-11 p. 328

Liv. 29.20 .11 p. 328

Liv. 36.2 .6 p. 328

Liv. 37.2.1. p. 328

Liv. 37.50 .8 p. 328

Liv. 38.35.10. p. 328

Liv. 38.42.5. p. 328

Liv. 38.60 .8 p. 328

Liv. 39.8.2. p. 328

Liv. 39.45. p. 328

Liv. 39.45.4, p. 328

Liv. 39.45 .5 p. 328

Liv. 40.1.1. p. $328-328$

Liv. 40.18 .3 p. $328-328$

Liv. 40.35.8. p. 328

Liv. 40.44.7. p. 328

Liv. 40.35.8. p. 328

Liv. 40.44.7. p. 328

Liv. 42.10 .10 p. 328

Liv. 42.10 .14 p. 328

Liv. 42.28 .6 p. 328

Liv. 45.12 .13 p. 328

Liv. 45.16.3. p. 328

Liv. 45.44 .2 p. 328

Liv. Per. 19.10. p. 217.

Liv. Per. 20.4 p. 217

\section{LUCII.IUS}

Luc. 1515 W, p. 228, 298, 318

\section{MACROBIUS}

Sat. 1.10.4, p. 268,

Sat. 1.10.23, p. 268.

Sat. 1.16, p. 236.

\section{OvIDIUS}

Fasti v. 663-664, p. 236.

\section{PlaUTO}

Amph. 153-158. p. 317.

Asin. 127ss., p. 317.

Bacc. 270-273. p. 317.

Capt. 1.2.11. p. 317.

Curc. 721-722., p. 317.

Epi. 23-24, p. 317.

Epid. 24-28. p. 317.

Pers. 53-69

Pers. 745-752, p. 316.

Poen. 181-186. p. 317.

Rud. 866-867. p. 317.

Stich. 722-728, p. 317.

Truc. 758, p. 253. 
Truc. 836-84, p. 317.

\section{PliniUs MAIUS}

Plin. Nat. hist. 5.95, p. 328

Plin. Nat. hist. 5.105., p. 238

Plin. Nat. hist. 5.111, p, 238

Plin. Nat. hist. 5.126, p. 238,

Plin. Nat. hist. 34.13. p. 194, 351,

\section{Plutarcus}

Plut. Cam. 12-13, p. 251.

Plut. Numa 10.6, p. 200.

\section{POLYBIUS}

Pol. 6.10.7, p. 208.

Pol. 6.12, p. 187.

Pol. 6.13.2, p. 306.

Pol. 6.14.6-8, p. 231.

Pol. 6.15.6, p. 215.

\section{SALLUSTIUS}

Sal. Cat. 31.4, p. 227.

\section{SUETONIUS}

Suet. Aug. 32.2-3, p. 268

Suet. Aug. 34-37, 270.

Suet. Claud. 23.1.

Suet. Hadrian. 22.13, p. 276, 279.

Suet. 33.1-3, 268.

\section{TACITUS [LUCIUS CORNELIUS TACITUS]}

Tac. Ann. 1.15, p. 329.

Tac. Ann. 1.80, p. 329.

Tac. Ann. 1.2, p. 281

Tac. Ann. 2.79, p. 329.

Tac. Ann. 6.11.1 p. 196, 233

Tac. Ann. 6.11.3, p. 277

Tac. Ann. 6.16, p. 214

Tac. Ann. 11.22.4, p. 251

Tac. Ann. 12.59-60, p. 284.

Tac. Ann. 13.28-29, p. 276

Tac. Ann. 14.4-41, p. 277 


\section{SÃO TOMÁS DE AQUINO}

Summa, II-II, q. 5, p. 12.

Summa, I-II, q. 90, p. 12.

Summa, I-II, q. 95, p. 12.

Summa, I-II, q. 97, p. 12.

De reg. princ. I, 15, p. 44

VALERIUS MAXIMUS

Val. Max. 2.8.2.p. 217

Val. Max. 7.7.3-4. P. 273

Val. Max. 7.7.6. p. 270

Val. Max. 6.1.10., p. 253

VARro (MARCUS TERRENTIUS VARRUS)

Varr. Ling. lat. 5.78, p. 247.

Varr. Ling. lat. 5.80, p. 228, 298, 318

Varr. Ling. lat. 5.81, p. 241, p. 253

Varr. Ling. lat. 5.87, p. 238

Varr. Ling. lat. 6.25.26, p. 332

Varr, Ling. lat. 6.30, p. 318.

Varr. Ling. lat 6.61, p. 318

Varr. Ling. lat 6.88, p. 206

Varr. Ling. lat 6.90, p. 251

Varr. Ling. lat 6.91, p. 251

Varr. Ling. lat 6.92, p. 251.

VELLEIUS

Vell. 2. 118, p. 329

VIRGILIUS

Virg. Aen. 6.535, p. 366

THE FRAGMENTS OF THE ROMAN HISTORIANS $(F R H)$

FRH 5, F15 (M. Porcio Cato), p. 212

FRH 5, F82 (M. Porcio Cato), p. 272

FRH 5, F97 (M. Porcio Cato), p. 290

FRH 5, F100 (M. Porcio Cato), p. 212

FRH 6, F24 (L. Cass. Hemina), p. 290

FRH 6, F35 (L. Cass. Hemina), p. 290

FRH 18, F7 (M. Aemil. Scaurus), p. 212

FRH 24, F94 (C. Claudius Quadrigarius), p. 212

FRH 25, F15 (Valério Antias), p. 250

FRH 26, F5 (Corn. Sisenna) p. 212

FRH 26, F117 (Corn. Sisenna), p. 212

FRH 26, F70 (Corn. Sisenna), p. 290

FRH 54, F2 (C. Caecilius Cornutus), p. 212 
